OPEN ACCESS

Edited by:

Lindi Masson

Burnet Institute, Australia

Reviewed by:

Ashu Sharma,

University at Buffalo, United States

Sinaye Ngcapu,

Centre for the AIDS Programme of Research in South Africa, South Africa Monalisa Manhanzva,

University of Cape Town, South Africa David Edwards,

Virginia Commonwealth University, United States

*Correspondence: Supriya D. Mehta Supriyad@uic.edu

Specialty section:

This article was submitted to Microbiome in Health and Disease, a section of the journal Frontiers in Cellular and Infection Microbiology

Received: 28 May 2021

Accepted: 30 August 2021 Published: 21 September 2021

Citation:

Mehta SD, Zulaika G, Otieno FO, Nyothach E, Agingu W, Bhaumik R,

Green SJ, van Eijk AM, Kwaro $D$ and Phillips-Howard PA (2021) High Prevalence of Lactobacillus crispatus Dominated Vaginal Microbiome Among Kenyan Secondary School

Girls: Negative Effects of Poor Quality Menstrual Hygiene Management and Sexual Activity. Front. Cell. Infect. Microbiol. 11:716537.

doi: 10.3389/fcimb.2021.716537

\section{High Prevalence of Lactobacillus crispatus Dominated Vaginal Microbiome Among Kenyan Secondary School Girls: Negative Effects of Poor Quality Menstrual Hygiene Management and Sexual Activity}

\author{
Supriya D. Mehta ${ }^{1 *}$, Garazi Zulaika ${ }^{2}$, Fredrick O. Otieno ${ }^{3}$, Elizabeth Nyothach ${ }^{4}$, \\ Walter Agingu ${ }^{3}$, Runa Bhaumik ${ }^{1}$, Stefan J. Green ${ }^{5}$, Anna Maria van Eijk ${ }^{2}$, Daniel Kwaro ${ }^{4}$ \\ and Penelope A. Phillips-Howard ${ }^{2}$ \\ 1 Division of Epidemiology \& Biostatistics, University of Illinois at Chicago, Chicago, IL, United States, 2 Department of Clinical \\ Sciences, Liverpool School of Tropical Medicine, Liverpool, United Kingdom, ${ }^{3}$ Nyanza Reproductive Health Society, \\ Kisumu, Kenya, ${ }^{4}$ Centre for Global Health Research, Kenya Medical Research Institute, Kisumu, Kenya, ${ }^{5}$ Department of \\ Internal Medicine and Genomics and Microbiome Core Facility, Rush University, Chicago, IL, United States
}

The vaginal microbiome (VMB) impacts numerous health outcomes, but evaluation among adolescents is limited. We characterized the VMB via 16S rRNA gene amplicon sequencing, and its association with Bacterial vaginosis (BV) and sexually transmitted infections (STIs; chlamydia, gonorrhea, trichomoniasis) among 436 schoolgirls in Kenya, median age 16.9 years. BV and STI prevalence was $11.2 \%$ and $9.9 \%$, respectively, with $17.6 \%$ of girls having any reproductive tract infection. Three community state types (CST) accounted for $95 \%$ of observations: CST-I L.crispatus-dominant ( $\mathrm{N}=178$, BV 0\%, STI $2.8 \%$, sexually active $21 \%$ ); CST-III L.iners-dominant ( $\mathrm{N}=152$, BV 3.3\%, STI $9.7 \%$, sexually active 35\%); CST-IV G.vaginalis-dominant ( $\mathrm{N}=83$, BV 51.8\%, STI 25.3\%, sexually active 43\%). In multivariable adjusted analyses, sexually active girls had increased odds of CST-III and CST-IV, and use of cloth to manage menses had 1.72fold increased odds of CST-IV vs. CST-I. The predominance of L.crispatus-dominated VMB, substantially higher than observed in prior studies of young adult and adult women in sub-Saharan Africa, indicates that non-optimal VMB can be an acquired state. Interventions to maintain or re-constitute L.crispatus dominance should be considered even in adolescents.

Keywords: vaginal microbiome, bacterial vaginosis (BV), sexually transmitted infection (STI), menstrual health, menstrual hygiene management, adolescents and youth, Sub-Saharan Africa (SSA) 


\section{INTRODUCTION}

Globally, adolescent girls and young women account for at least one-third of the 357 million curable sexually transmitted infections (STIs) occurring each year (Blum and NelsonMmari, 2004; Newman et al., 2015; Population Reference Bureau, 2021). STIs are syndemic with HIV. UNAIDS reports that $15 \%$ of all women living with HIV are aged 15-24 years old, $80 \%$ of whom live in sub-Saharan Africa, and $31 \%$ of new HIV infections are among adolescent girls (Amornkul et al., 2009). In western Kenya, HSV-2 increases dramatically from 10\% in 13-14 year-old girls to $28 \%$ in 15-19 year-olds (Otieno et al., 2015; Kenya Ministry of Health National AIDS and STI Control Programme (NASCOP), 2020). HIV prevalence increases from $1.2 \%$ among $15-19$ year-old girls to $3.4 \%$ of those aged $20-24$, compared to $0.5 \%$ and $0.6 \%$ for males of the same age (Amornkul et al., 2009). Among adolescent girls, the HIV/STI epidemic overlaps with broader reproductive health concerns. For example, to attend school and obtain necessities such as sanitary products, soap and underwear, girls often engage in exchange sex (Phillips-Howard et al., 2015). Menstrual hygiene management (MHM) is a pervasive problem across low- and middle-income countries and a lack of MHM materials negatively impacts girls' health and schooling (Sommer et al., 2016). Phillips-Howard et al. conducted a cluster randomized study of 644 girls aged 14-16 years old, comparing reusable menstrual cups to control condition of menstrual hygiene counseling (Zevin et al., 2016). After one year, menstrual cup use resulted in $35 \%$ reduction $(\mathrm{p}=0.034)$ in Bacterial vaginosis (BV) prevalence and $52 \%$ reduction $(\mathrm{p}=0.039)$ in STI prevalence compared to control condition. This decrease in STIs and BV may have been mediated by sexual practices, or the menstrual cups themselves.

Bacterial vaginosis affects $20-50 \%$ of general population women in sub-Saharan Africa (Torrone et al., 2018), and increases the risk of HIV acquisition and transmission (accounting for up to 15\% of HIV infections) (Atashili et al., 2008), multiple adverse pregnancy outcomes (Eschenbach et al., 1984; Hay et al., 1994; Ralph et al., 1999), and is consistently associated with chlamydia, gonorrhea, HPV and HSV-2 (van de Wijgert et al., 2014). BV typically represents a vaginal microbiome (VMB) that is highly diverse (i.e., having many different types of bacteria) and depletion of Lactobacillus species (McKinnon et al., 2019). Using 16S rRNA gene amplicon sequencing, commonly occurring vaginal community state types (CST) have been identified (Ravel et al., 2011). CST-I (Lactobacillus crispatus dominated) has been considered an advantageous state, due to the demonstrated protective mechanisms of L. crispatus [e.g., maintaining acidic vaginal $\mathrm{pH}$, inhibiting growth of pathogenic bacteria, activating immune cells, production of antibacterial substances, etc. (Lewis et al., 2017; Kovachev, 2018)], and due to the consistent protective association of L. crispatus against BV, HIV, HPV and other sexually transmitted infections (STIs) (van de Wijgert et al., 2014; McKinnon et al., 2019). On the other hand, CST-IV (a high diversity vaginal community that is usually depleted of lactobacilli) is considered a non-optimal vaginal microbiome, or "molecular BV" (McKinnon et al., 2019), and has been associated with epithelial barrier disruption and enhanced immune activation, even in the absence of clinical BV diagnosis (Zevin et al., 2016). The VMB in relation to menstrual hygiene practices and period characteristics (e.g., duration, cramping, flow) has not been rigorously assessed, and is especially lacking among adolescent girls.

We are currently evaluating the effect of menstrual cups on the VMB, BV, and STIs among secondary schoolgirls enrolled in a cluster randomized controlled trial in Siaya County, western Kenya (Zulaika et al., 2019). In the current analysis, we characterized the baseline VMB and factors associated with $\mathrm{VMB}$ composition in relation to sexual activity, MHM practices and menstrual characteristics, and presence of $\mathrm{BV}$ or STIs.

\section{MATERIALS AND METHODS}

This study was approved by the institutional review boards of the Kenya Medical Research Institutes (KEMRI, SERU \#3215), Liverpool School of Tropical Medicine (LSTM, \#15-005), and University of Illinois at Chicago (UIC, \#2017-1301).

\section{Study Setting}

This study used baseline data and biological specimens from the Cups and Community Health (CaCHe, pronounced "Cash-Ay") study, a prospective cohort study of adolescent secondary school girls in Siaya County. The CaCHe study is nested in Cups or Cash for Girls (CCG), a large cluster randomized controlled trial assessing the impact of menstrual cups and cash transfer interventions on a composite outcome of school dropout, HIV and HSV-2 (Zulaika et al., 2019) (ClinicalTrials.gov NCT03051789). Siaya County area is positioned $400 \mathrm{~km}$ west of Nairobi, adjacent to Lake Victoria. Siaya County is largely rural and Bondo is the largest town with approximately 35,000 inhabitants. From the most recent Demographic and Health Survey, in Siaya County, women's median age of first sexual intercourse is 16.6 years (versus 19.3 years for Nairobi and 18.0 years nationally), 19.1 years for first marriage (versus 22.1 years for Nairobi and 20.2 years nationally), and 18.4 years for first birth (versus 22.7 years for Nairobi and 20.3 years nationally) (Kenya National Bureau of Statistics and Kenya Ministry of Health, 2014). Among adult women surveyed, 15.1\% had completed secondary education or more in Siaya County, compared to $51.4 \%$ of women in Nairobi and $26.9 \%$ nationally. The prevalence of HIV among adult women in the area was estimated at $25.3 \%$ in 2015 (Kenya Ministry of Health, 2021). In Health and Demographic Surveillance (HDSS) rounds taking place 2011 to 2016, HIV incidence between rounds among 15-24 year-old women and girls was $8.9 \%$, compared to $3.2 \%$ among boys and men of same age (Borgdorff et al., 2018).

\section{Study Design and Participants}

The CCG trial is an open-label, 4-arm, school-cluster randomized controlled superiority trial. Schools were allocated into 4 arms 
(1:1:1:1) via block randomization: (1) provision of menstrual cups with training on safe cup use and care; (2) conditional cash transfer (CCT) based on $>80 \%$ school attendance in previous term; (3) menstrual cup and CCT; and (4) usual practice. All girls received puberty and hygiene education.

For the $\mathrm{CaCHe}$ study, nested within the CCG trial, we aimed to enroll $20 \%$ of girls in the cup only and control arms of the CCG trial. Eligibility for $\mathrm{CaCHe}$ followed eligibility for CCG: attendance at a selected school, being a resident of the study area, provision of assent and parental/guardian consent, and girls had to report established menses ( $>3$ times). Girls were excluded if they declared pregnancy at baseline.

\section{Data Collection}

Following written informed parental consent and assent from minors, participants self-completed a tablet-based survey in their language of choice (English or DhoLuo) to obtain sociodemographic information and to assess sexual and MHM practices. Study nurses and counsellors trained in research and survey administration provided assistance or conducted interviews as needed. Socio-demographic data included age and assessment of household amenities, including water source, light source, latrine type, and possession of a television. Household mobile phone possession was $98 \%$ and was not used in the analyses. A household amenity score having range $0-4$ was created, with one pint each for piped water source, electricity for light source, flush toilet, and possession of a television. Ever having sexual intercourse was assessed in two questions to differentiate forced sex from willing sex, and via a series of questions around exchange sex (sex in exchange for money, goods, or favors).

\section{Sample Size}

$\mathrm{CaCHe}$ was designed to estimate the effect of menstrual cups on girls' risk of BV, with an anticipated cumulative event rate of 30$40 \%$ among controls occurring over 30 months. In a design of 6 repeated measurements having $\mathrm{AR}(1)$ covariance structure, correlation between observations on the same subject ranging 0.25 to 0.4 , and accounting for $20 \%$ loss to follow-up, group sample sizes of 220 in cup arm and 220 in control arm would achieve $>80 \%$ power to detect $25 \%$ reduced prevalence of $\mathrm{BV}$ for the cup arm compared to control arm when $\mathrm{BV}$ prevalence is $30 \%$, and $97 \%$ power when prevalence is $40 \%$ [ $p=0.05$ two-sided test, two proportions in a repeated measures design; PASS v15 (Hintze, 2014)].

\section{Specimen Collection}

At baseline and each follow-up visit, girls were asked to take four self-collected vaginal swabs. The first swab obtained was for $16 \mathrm{~S}$ rRNA gene amplicon sequencing (microbiome), the second for $\mathrm{BV}$, the third for detection of $C$. trachomatis (CT) and $N$. gonorrhoeae (NG), and the fourth for detection of T. vaginalis (TV). Prior to vaginal swab collection, girls were given oral and graphic instruction on how to collect the swabs. Girls were instructed to insert each swab approximately 2-3 centimeters into the vaginal opening and to twirl the swab for 20 seconds. Each girl obtained her swabs in a private, enclosed area, with a nurse or female field assistant aiding girls with sample collection one on one. The nurses or research assistant handed the swabs to the girls sequentially, timing each collection for 20 seconds while girls were instructed to twirl, and then retrieving before passing the next swab. Nurses and research assistants prepared smears for BV immediately, with a lab assistant checking each slide for sufficiency after air drying. Swabs for amplicon sequencing, CT/NG, and TV were immediately placed on ice packs in coolers for transport.

\section{Detection of Bacterial Vaginosis, Sexually Transmitted Infections, and HIV}

Upon receipt at the lab, specimens for amplicon sequencing were placed at $-80^{\circ} \mathrm{C}$ until shipment to Chicago for processing. Vaginal swabs for amplicon sequencing were collected using OMNIgene Vaginal kits (OMR-130; DNA Genotek ${ }^{\mathrm{TM}}$ ). Swabs for CT/NG were shipped weekly for processing at the University of Nairobi Institute for Tropical and Infectious Diseases (UNITID). Following manufacturer protocol, vaginal swabs were tested for CT/NG using the GeneXpert (Cepheid, Sunnydale, California, US). Swabs for TV were processed immediately upon receipt using the OSOM TV antigen detection assay (Sekisui, Lexington, MA, US). Air-dried smears prepared from self-collected vaginal swabs were Gram stained and evaluated according to Nugent's criteria within 48 hours of receipt; a score of 7-10 was defined as BV (Nugent et al., 1991). Finger-stick whole blood collected in EDTA tubes were tested for HIV according to Kenyan national guidelines (National AIDS and STI Control Programme, 2015). HIV positive girls were linked to care.

\section{STI and BV Treatment}

CT, NG, and TV were treated following Kenyan National guidelines (National AIDS et al., 2015). Treatment of BV was with $2 \mathrm{~g}$ of tinidazole once daily for two days. While not a specified regimen in the Kenyan national guidelines, we followed this alternative treatment recommendation as per U.S. Centers for Disease Control and Prevention (CDC, 2015), British Association for Sexual Health and HIV (BASHH, 2021), and International Union against Sexually Transmitted Infections/ World Health Organization (IUSTI/WHO) (Sherrard et al., 2018), due to concerns of greater likelihood of gastrointestinal symptoms and decreased adherence with the longer duration regimens for metronidazole. While guidelines currently do not recommend treatment for asymptomatic BV, we treated all girls with Nugent score 7-10 due variability in recognition and reporting of symptoms (Lewis and Laurent, 2020), and potential benefits as reported in BASHH and IUSTI/WHO guidelines (Sherrard et al., 2018; BASHH, 2021), and due to the high proportion of girls reporting vaginal discharge (23\%) overall, which did not differ by BV or STI status (Table 1). Treatment was documented for 48/49 (98\%) of girls with BV, 27/ 27 (100\%) with CT, 6/6 (100\%) NG, and 13/14 (93\%) TV. 
TABLE 1 | Distribution of baseline characteristics by bacterial vaginosis (BV) status and sexually transmitted infection (STI) status.

\begin{tabular}{|c|c|c|c|c|c|c|c|}
\hline \multirow[t]{2}{*}{ Variables $^{3}$} & \multirow{2}{*}{$\begin{array}{c}\text { Total } \mathrm{N}=436 \mathrm{n} \\
(\%)\end{array}$} & \multicolumn{2}{|c|}{ BV Status $^{1}$} & \multirow{2}{*}{$\begin{array}{l}\text { P- } \\
\text { value }\end{array}$} & \multicolumn{2}{|c|}{ STI Status ${ }^{2}$} & \multirow{2}{*}{$\begin{array}{c}\text { P- } \\
\text { value }^{4}\end{array}$} \\
\hline & & $\begin{array}{c}\text { Positive, } \mathrm{N}=49 \\
\text { n (\%) }\end{array}$ & $\begin{array}{l}\text { Negative, } \\
\mathrm{N}=387 \text { n (\%) }\end{array}$ & & $\begin{array}{c}\text { Positive, } \mathrm{N}=43 \\
\mathrm{n}(\%)\end{array}$ & $\begin{array}{l}\text { Negative, } \\
\mathrm{N}=393 \mathrm{n}(\%)\end{array}$ & \\
\hline \multicolumn{8}{|l|}{ Socio-Demographics } \\
\hline Median Age in years $(\mathrm{IQR})^{5}$ & $16.9(16.0-17.9)$ & 17.7 (16.5-18.6) & $16.9(16.0-17.7)$ & $<0.001$ & 17.7 (16.0-18.5) & $16.9(16.0-17.8)$ & 0.013 \\
\hline Age in years, categories & & & & 0.024 & & & 0.021 \\
\hline $14-15$ & $52(11.9)$ & $3(6.1)$ & $49(12.7)$ & & $3(7.0)$ & $49(12.5)$ & \\
\hline 16 & $113(25.9)$ & $9(18.4)$ & $104(26.9)$ & & $8(16.0)$ & $105(26.7)$ & \\
\hline 17 & $121(27.8)$ & $11(22.5)$ & $110(28.4)$ & & 7 (16.3) & $114(29.0)$ & \\
\hline 18 & $96(22.0)$ & $13(26.5)$ & $83(21.5)$ & & $16(37.2)$ & $80(20.4)$ & \\
\hline $19-22$ & $54(12.4)$ & $13(26.5)$ & 41 (10.6) & & $9(20.9)$ & 45 (11.5) & \\
\hline Latrine Type & & & & 0.883 & & & 0.181 \\
\hline Flush toilet & $50(11.6)$ & $5(10.4)$ & $45(11.8)$ & & $7(17.1)$ & $43(11.0)$ & \\
\hline Traditional pit & $197(45.7)$ & $23(47.9)$ & $174(45.4)$ & & $17(41.5)$ & $180(46.2)$ & \\
\hline Ventilated improved pit & $171(39.7)$ & $18(37.5)$ & $153(40.0)$ & & $14(34.2)$ & $157(40.3)$ & \\
\hline Bush, field, other & $13(3.0)$ & $2(4.2)$ & $11(2.9)$ & & $3(7.3)$ & $10(2.6)$ & \\
\hline Water Source & & & & 0.408 & & & 0.611 \\
\hline Bore hole & $69(16.1)$ & $4(8.5)$ & $65(17.0)$ & & $6(14.6)$ & $63(16.2)$ & \\
\hline Surface & 255 (59.3) & $33(70.2)$ & $222(58.0)$ & & $23(56.1)$ & 232 (59.6) & \\
\hline Pipe in house & $23(5.4)$ & $2(4.3)$ & $21(5.5)$ & & $1(2.4)$ & $22(5.7)$ & \\
\hline Rainwater & 83 (19.3) & $8(17.0)$ & 75 (19.6) & & $11(26.8)$ & $72(18.5)$ & \\
\hline Source of Light & & & & 0.258 & & & 0.469 \\
\hline Electricity & $95(22.0)$ & 7 (14.6) & $88(23.0)$ & & 8 (19.5) & $87(22.3)$ & \\
\hline Kerosene & $171(39.7)$ & $23(47.9)$ & $148(38.6)$ & & $22(53.7)$ & $149(38.2)$ & \\
\hline Tin lamp & $61(14.2)$ & $10(20.8)$ & $51(13.3)$ & & 5 (12.2) & $56(14.4)$ & \\
\hline Solar & 83 (19.3) & $6(12.5)$ & $77(20.1)$ & & $5(12.2)$ & $78(20.0)$ & \\
\hline Other & $21(4.9)$ & $2(4.2)$ & $19(5.0)$ & & $1(2.4)$ & $20(5.1)$ & \\
\hline Has Television in Home & $104(24.1)$ & $8(16.7)$ & $96(25.1)$ & 0.200 & 8 (19.5) & $96(24.6)$ & 0.468 \\
\hline $\begin{array}{l}\text { Median household amenities (IQR): summed score of } \\
\text { flush toilet, piped water, electricity, television }\end{array}$ & $0(0-1)$ & $0(0-1)$ & $0(0-1)$ & 0.251 & $0(0-1)$ & $0(0-1)$ & 0.894 \\
\hline \multicolumn{8}{|l|}{ Health Status } \\
\hline HIV Positive & $6(1.4)$ & $3(6.3)$ & $3(0.8)$ & 0.020 & $0(0.0)$ & $6(1.5)$ & $>0.999$ \\
\hline Reports having vaginal discharge & $98(23.0)$ & $14(29.2)$ & $84(22.2)$ & 0.282 & $10(25.0)$ & $88(22.8)$ & 0.753 \\
\hline Reports having pain on urination & $27(6.3)$ & $6(12.5)$ & $21(5.6)$ & 0.063 & $6(15.0)$ & $21(5.4)$ & 0.018 \\
\hline Past 6 months, been to health facility & $246(57.1)$ & $30(62.5)$ & $216(56.4)$ & 0.421 & $25(61.0)$ & $221(56.7)$ & 0.596 \\
\hline Reported antibiotic use past 30 days & $85(20.0)$ & $9(18.8)$ & $76(20.1)$ & 0.825 & $7(17.5)$ & $78(20.2)$ & 0.683 \\
\hline Body mass index, median (IQR) & $21.6(20.0-23.3)$ & $22.6(21.4-24.5)$ & $21.4(19.9-23.2)$ & $<0.001$ & $21.5(20.0-23.6)$ & $21.6(20.0-23.3)$ & 0.799 \\
\hline Body mass index, category & & & & 0.038 & & & 0.085 \\
\hline Underweight $(<18)$ & $25(5.8)$ & $0(0.0)$ & $25(6.6)$ & & $5(12.2)$ & $20(5.2)$ & \\
\hline Normal (18-25) & $350(81.8)$ & $37(78.7)$ & $313(82.2)$ & & $29(70.3)$ & $321(83.0)$ & \\
\hline Overweight or obese $(>25)^{a}$ & $53(12.4)$ & $10(21.3)$ & $43(11.3)$ & & $7(17.1)$ & $46(11.9)$ & \\
\hline \multicolumn{8}{|l|}{ Sexual Exposures } \\
\hline Past 6 months: Touched indecently by a man or boy & $69(16.0)$ & $12(25.0)$ & $57(14.9)$ & 0.072 & $8(19.5)$ & $61(15.6)$ & 0.520 \\
\hline Past 6 months: Harassed for sex outside of school & $175(40.6)$ & $20(41.7)$ & $155(40.5)$ & 0.874 & 15 (36.6) & $160(41.0)$ & 0.582 \\
\hline Past 6 months: Harassed for sex at school & $45(10.4)$ & $8(16.7)$ & $37(9.7)$ & 0.135 & $2(5.9)$ & $43(11.0)$ & 0.290 \\
\hline Ever had sex willingly & $100(23.2)$ & $22(45.8)$ & $78(20.4)$ & $<0.001$ & $23(56.1)$ & $77(19.7)$ & $<0.001$ \\
\hline Ever forced or tricked to have sex & $70(16.2)$ & $9(18.8)$ & $61(15.9)$ & 0.617 & $12(29.3)$ & $58(14.9)$ & 0.017 \\
\hline Any sexual exposure ever & & & & 0.001 & & & $<0.001$ \\
\hline No sex ever & $301(69.8)$ & $25(52.1)$ & $276(72.1)$ & & $16(39.0)$ & $285(73.1)$ & \\
\hline Had sex willingly & $60(13.9)$ & $14(29.2)$ & $46(12.0)$ & & $13(31.7)$ & $47(12.1)$ & \\
\hline Forced or tricked intercourse & $30(7.0)$ & $1(2.1)$ & $29(7.6)$ & & $2(4.9)$ & $28(7.2)$ & \\
\hline Had sex willingly, and forced or tricked intercourse & $40(9.3)$ & $8(16.7)$ & $32(8.4)$ & & $10(24.4)$ & $30(7.7)$ & \\
\hline \multicolumn{8}{|l|}{ Menstruation and Management } \\
\hline Median age in years at first period (IQR) & $14(14-15)$ & $15(14-15)$ & $14(14-15)$ & 0.126 & $14(13.5-15)$ & $14(14-15)$ & 0.537 \\
\hline Early menarche (first period < 13 years of age) & $19(4.6)$ & $0(0)$ & $19(5.2)$ & 0.147 & $6(14.6)$ & $13(3.5)$ & 0.001 \\
\hline Had period in the past 6 weeks & $405(94.0)$ & $46(95.8)$ & $359(93.7)$ & 0.755 & $40(97.6)$ & $365(93.6)$ & 0.495 \\
\hline Pad used at last period & $405(94.0)$ & $46(95.8)$ & $359(93.7)$ & 0.755 & $39(95.1)$ & 366 (93.9) & $>0.999$ \\
\hline Cloth used for part or all of last period & $108(25.1)$ & $14(29.2)$ & $94(24.5)$ & 0.486 & $13(31.7)$ & $94(24.4)$ & 0.302 \\
\hline
\end{tabular}

${ }^{1} \mathrm{BV}$ is defined as Nugent score 7-10.

2 STI is a composite of positive for C. trachomatis, N. gonorrhoeae, and/or T. vaginalis.

${ }^{3}$ Not all cells sum to $N$ due to missing values.

${ }^{4}$ P-value by chi-square test unless otherwise noted; Fisher exact test used for categorical comparisons where any cell count was less than 5.

${ }^{5}$ Wilcoxon rank sum test used for comparison of non-normally distributed continuous variables.

a "Overweight and obese" includes $n=4$ girls with $B M I>30$. 
DNA Extraction and Amplicon Sequencing and Annotation

Genomic DNA (gDNA) was used as template for PCR amplification of the V3-V4 variable region of bacterial $16 \mathrm{~S}$ rRNA gene according to a two-stage PCR protocol using primers $341 \mathrm{~F}$ and $806 \mathrm{R}$, as described previously (Naqib et al., 2018; Mehta et al., 2020). After pooling of barcoded samples, amplicons were sequenced on an Illumina MiSeq instrument, implementing V3 chemistry (600 cycles). DNA extraction, library preparation and sequencing were performed by the Genome Research Core (GRC) at the University of Illinois at Chicago (UIC). Forward and reverse reads were merged using the software package PEAR (Zhang et al., 2014). Quality and primer trimmed sequence data were then processed using a standard bioinformatics pipeline for chimera removal, and annotation was conducted by University of Maryland Institute for Genomic Science (UMD IGS) (Holm et al., 2019). Subsequently, a biological observation matrix was generated at the lowest taxonomic level identifiable. Vaginal CST were identified in a reference dataset using nearest centroid classification (VAginaL community state typE Nearest CentroId clAssifier; VALENCIA) as described in (France et al., 2020). Data were filtered to retain taxa that contributed at least $0.05 \%$ of the total sequence reads, resulting in retention of 26 vaginal taxa. There were 5 observations with $<5,000$ sequence reads which were excluded from analyses.

\section{Statistical Analysis}

In this cross-sectional analysis, we examined two questions: (1) how the baseline VMB composition varied by whether girls were sexually active, and BV and/or STI presence; (2) how the baseline VMB composition varied by menstrual management practices and period characteristics.

Stacked bar plots summarizing taxa with highest relative abundance were created using Stata/SE 15. Alpha diversity indices were calculated at the amplicon sequence variant level using filtered data after rarefaction to a depth of 5,000 sequence per sample (vegan) (Gihring et al., 2012). We tested for global differences in vaginal community composition by $\mathrm{BV}$ and nonulcerative STI status using analysis of similarity (ANOSIM) of the Bray Curtis resemblance matrix; ANOSIM is a nonparametric statistical test that assesses whether observations within a group are more similar to each other than to another group, in this way detecting differences between groups (Clarke, 1993). We visualized the relationship of global bacterial communities by BV and STI status using non-metric multidimensional scaling (NMDS) of bootstrapped averages of centroids with 100 replicates for each of the four groups representing outcome states (negative for both BV and STIs, positive for STI only, positive for BV only, positive for BV and STI). Bootstrapping is a resampling procedure that was used to estimate standard errors that allowed statistical inference on the differences between groups (Paliy and Shankar, 2016). ANOSIM and NMDS procedures were conducted in Primer-E, version 7, United Kingdom. We used multinomial logistic regression to quantify associations between explanatory factors (e.g., age, material used to manage menses, sexual activity) and CST, and Poisson regression with robust variance estimate (Barros and Hirakata, 2003) was used to quantify associations between explanatory factors and BV or STI. Because school was the unit of randomization and there were differences in distribution of socio-demographics, sexual activity, BV and STIs by school (Supplementary Table 1), we included a random effect for school in models of CST, BV, and STI. Multinomial logistic regression and Poisson regression were conducted in Stata/SE 15. Explanatory variables that were associated with outcomes at the $\mathrm{p}<0.10$ level were entered in multivariable regression, and those with Wald $\mathrm{p}$-value $<0.05$ were retained in multivariable models.

To identify specific taxa associated with Nugent BV and STIs, we used stability selection for feature selection [stabs package, implemented in R (Meinshausen and Bühlmann, 2010)]. In this approach, we applied ElasticNet regression to 250 randomly generated subsets of the vaginal microbiome data and used a cutoff of $\mathrm{p}<0.20$ in combination with detection of a specific taxa in at least $60 \%$ of subsets. We chose ElasticNet regression as its ridge regression penalty supports inclusion of highly correlated variables while maintaining sparsity (Zou and Hastie, 2005). Prior to feature selection, data were center log ratio transformed following geometric Bayesian multiplicative prior imputation of zeros [zCompositions package, implemented in $\mathrm{R}$ (PalareaAlbaladejo and Martin-Fernandez, 2015)], to address sparsity while maintaining read depth. As a supplementary analysis, we also identified taxa that differed by BV and STI status using similarity of percentage analysis (Clarke, 1993), which determined the percent contributions of individual taxa to the Bray Curtis dissimilarity between groups (Primer-E, version 7, United Kingdom).

\section{RESULTS}

\section{Study Population}

The median age of girls was 16.9 years (interquartile range 16.0 17.9) (Table 1). The median household amenities score - a summed score of flush toilet, piped water, electricity, and television - was zero. Majority of girls reported traditional pit (45.7\%) for latrine, surface water as main water source (59.3\%), and kerosene for lighting (39.7\%), with $24.1 \%$ having a television. Many girls reported having been to a health facility in the past 6 months, with $20 \%(\mathrm{n}=85)$ reporting antibiotic use in the past 30 days, primarily for fever $(\mathrm{n}=64)$ and generally in combination with other symptoms (such as respiratory or diarrhea). Nearly one-third (30.2\%) of girls reported any prior sexual intercourse and, of those, 54\% reported that they had been forced or tricked to have sex. Among sexually active girls, just $8.5 \%$ reported using a hormonal contraceptive for family planning ( $\mathrm{n}=6$ injectable, $\mathrm{n}=4$ implant, $\mathrm{n}=1$ pill) and this sparsity prevented evaluating associations with BV, STIs, or CST. 


\section{Bacterial Community Composition Differed by BV and STI Status}

Three vaginal CSTs accounted for 95\% of VMBs: $L$. crispatus dominant CST-I (41\%), L. iners dominant CST-III (35\%), and non-optimal CST-IV (19\%) (Table 2 and Figure 1). There were 12 (2.8\%) girls with L. gasseri dominant CST-II and 8 (1.8\%) girls with L. jensenii dominant CST-V. In keeping with the associations between non-optimal CST-IV reported in the literature (McKinnon et al., 2019), the prevalence of BV (52.4\%) and non-ulcerative STIs $(24.4 \%)$ was high within CSTIV, lowest in CST-I ( $0 \% \mathrm{BV}, 2.8 \%$ non-ulcerative STI), and intermediate in CST-III (3.3\% BV, 9.8\% non-ulcerative STI). Overall, $59.8 \%$ of girls within CST-IV were detected with BV and/or non-ulcerative STI, compared to $2.8 \%$ within CST-I and 12.4\% within CST-III (Table 2 and Figure 2).

The global difference in bacterial community composition by BV and STI outcome was statistically significant (ANOSIM test, $\mathrm{p}=0.001$; Supplementary Table 2); all pairwise comparisons were statistically significant $(p=0.001$, each) except for the comparison of communities in which the participant was positive for both BV and STI versus positive for BV and negative for STI $(p=0.871)$. This difference in VMB composition is visualized in non-metric dimensional plots of the bootstrapped averages of the centroids of the four possible states of outcome (Figure 3A). The distribution of CST differed by BV and/or STI outcome (Figure 3B) and results of stability selection identified specific taxa differences between BV and STI outcomes: L. jensenii, Dialister succinatiphilus, Sneathia sanguinegens, Megasphaera, and Lactobacillus spp. (Lactobacillus identified at the genus level, but species was not identified) were associated with BV, while Megasphaera, Atopobium vaginae, S. sanguinegens, and L. crispatus were associated with STI (Table 3 and Figure 3C). In supplementary analysis, the taxa contributing most to Bray Curtis dissimilarity between BV status (Supplementary Table 3) and STI status (Supplementary Table 4) were similar, with notable differences: G. vaginalis had strong contribution to BV positive and STI positive status, and while ElasticNet identified L. jensenii but not L. crispatus in association with BV, L. crispatus was the top differentiating taxa by Bray Curtis dissimilarity while L. jensenii was not identified as an important taxon. Girls with BV and STI had higher alpha diversity metrics (Shannon, Simpson, evenness, richness) (Figures 4, 5), and this is in keeping with the greater frequency of diverse CST-IV among girls with BV and STIs.

\section{The Distribution of Community State Type Varied by Sociodemographic and Behavioral Characteristics}

Household amenities scores were higher for girls with CST-II and CST-V $(\mathrm{p}=0.041)$, though numbers are small in these CSTs (Table 2). The median BMI was marginally higher for girls with CST-IV ( $\mathrm{p}=0.094)$, in keeping with the association we observed between BMI and BV. There were no statistically significant differences in MHM or period characteristics by CST, though cloth use was more common in CST-III (29.1\%) and CST-IV (31.3\%) than CST-I (19.3\%) $(\mathrm{p}=0.143)$, and when restricted to these three CSTs the difference was statistically significant $(\mathrm{p}=0.050)$. Notably, any sexual activity (willing or forced) was reported by $43.8 \%$ of girls with CST-IV, compared to $21 \%$ of girls with CST-I, and $35.1 \%$ of girls with CST-III. Looking at this in transpose, among girls reporting never being sexually active, $46.6 \%$ had CST-I VMB, 32.9\% with CST-III, and $15.1 \%$ with CST-IV, while among girls reporting having been sexually active, $28.7 \%$ had CST-I, $41.1 \%$ CST-III, and $27.1 \%$ CSTIV (Figure 2).

In multinomial logistic regression (Supplementary Table 5) examining one covariate at a time (i.e., unadjusted), for each one year increase in age, there was a $31 \%$ increase in odds of CST-IV relative to CST-I (OR=1.31; 95\% CI: 1.08 - 1.59) and increasing household amenity score was inversely associated with CST-III $(\mathrm{OR}=0.71 ; 95 \% \mathrm{CI}: 0.55$ - 0.90) relative to CST-I. Ever having been sexually active was associated with increased likelihood of CST-III (OR=2.03; 95\% CI: $1.56-2.65)$ and CST-IV (OR=2.92; 95\% CI: $1.26-6.77$ ), as was cloth use during last period (CST-III $\mathrm{OR}=1.72$; 95\% CI: 1.28 - 2.31; CST-IV OR=1.90; 95\% CI: 1.07 3.37). Increasing BMI was associated with decreasing likelihood of being in CST-III (OR=0.93; 95\% CI: 0.87 - 0.99) or CST-V $(\mathrm{OR}=0.84 ; 95 \% \mathrm{CI}: 0.71$ - 0.99$)$ relative to CST-I. In multivariable multinomial logistic regression analyses simultaneously adjusted for all variables presented (Table 4), all of these associations remained statistically significant $(\mathrm{p}<0.05$, two sided), with no evidence of strong confounding.

\section{Prevalence of Bacterial Vaginosis and Sexually Transmitted Infections}

The prevalence of STIs was 9.9\% (3.0\% TV, 6.2\% CT, 1.4\% NG), and the prevalence of BV was $11.2 \%$. There was substantial coinfection with $31 \%$ of girls with BV having an STI, and $35 \%$ of girls with an STI also having BV (Figure 6).

Only two variables were associated with both BV and STI: increasing age and ever having had sex willingly (Table 1). Increasing BMI was associated with $\mathrm{BV}$, but not with STIs. Unsurprisingly, ever reporting willing and/or forced/tricked sexual activity was more common among girls with detected BV or STI, though $52 \%$ of girls with BV and $39 \%$ of girls with STI reported never having had any type of sexual intercourse. Among girls who reported any sexual exposure, the distribution of condom use, number of lifetime partners, and age of most recent male sex partner did not differ by BV or STI status (Supplementary Table 6). No individual MHM practices were associated with BV or STI.

In multivariable adjusted log binomial regression analyses (Table 5), BV was more prevalent with increasing age (adjusted prevalence rate ratio $[\mathrm{aPRR}]=1.24$ per one year increase; $95 \% \mathrm{CI}$ : 1.15 - 1.33), increasing BMI ( $\mathrm{PPRR}=1.13$ per one unit increase; 95\% CI: $1.11-1.15)$, and sexual intercourse ( $\mathrm{aPRR}=2.17$; 95\% CI: 1.41 - 3.35), while increasing household amenities score was 
TABLE 2 | Distribution of characteristics by vaginal microbiome community state type ${ }^{1}$.

\begin{tabular}{|c|c|c|c|c|c|c|}
\hline & $\begin{array}{c}\text { CST-I, N=177 } \\
\text { L. crispatus dominant } \\
\mathrm{n}(\%)\end{array}$ & $\begin{array}{c}\text { CST-II, } \mathrm{N}=12 \\
\text { L. gasseri dominant } \\
\mathrm{n}(\%)\end{array}$ & $\begin{array}{c}\text { CST-III, N=153 } \\
L \text { iners Dominant } \\
\mathrm{n}(\%)\end{array}$ & $\begin{array}{c}\text { CST-IV, } N=81 \\
\text { G. vaginalis dominant } \\
n(\%)\end{array}$ & $\begin{array}{c}\mathrm{CST}-\mathrm{V}, \mathrm{N}=8 \\
\text { L. jensenii dominant } \\
\mathrm{n}(\%)\end{array}$ & $\begin{array}{l}{ }^{3} \mathrm{P}- \\
\text { value }\end{array}$ \\
\hline Bacterial Vaginosis (BV) & $0(0.0)$ & $1(8.3)$ & $5(3.3)$ & $43(52.4)$ & $0(0.0)$ & $<0.001$ \\
\hline Sexually Transmitted Infection (STI) & $5(2.8)$ & $2(16.7)$ & $15(9.8)$ & $20(24.4)$ & $0(0.0)$ & $<0.001$ \\
\hline C. trachomatis $(\mathrm{CT})$ & $4(2.3)$ & $2(16.7)$ & $8(5.2)$ & $12(14.6)$ & $0(0.0)$ & 0.002 \\
\hline N. gonorrhoeae (NG) & $1(0.6)$ & $0(0.0)$ & $3(2.0)$ & $2(2.4)$ & $0(0.0)$ & 0.522 \\
\hline T. vaginalis (TV) & $0(0.0)$ & $0(0.0)$ & 5 (3.3) & $9(11.0)$ & $0(0.0)$ & $<0.001$ \\
\hline BV and/or STI (CT, NG, TV) & $5(2.8)$ & $3(25.0)$ & $19(12.4)$ & $49(59.8)$ & $0(0.0)$ & $<0.001$ \\
\hline $\begin{array}{l}\text { Ever had sex, willingly and/or forced } \\
\text { or tricked }\end{array}$ & $37(21.0)$ & $3(25.0)$ & $53(35.1)$ & $35(43.8)$ & $1(12.5)$ & 0.001 \\
\hline Median age in years $(\mathrm{IQR})^{4}$ & $17(16-18)$ & $17(16-17.8)$ & $17(16-18)$ & $17(16-18)$ & $16.3(17.5-18)$ & 0.284 \\
\hline $\begin{array}{l}\text { Median material goods point score } \\
(\mathrm{IQR})^{4}\end{array}$ & $0(0-1)$ & $1(0.25-1)$ & $0(0-1)$ & $0(0-1)$ & $0.5(0-1.75)$ & 0.041 \\
\hline Latrine Type & & & & & & 0.748 \\
\hline Flush toilet & $24(13.6)$ & $3(25.0)$ & $13(8.6)$ & $9(11.3)$ & $1(12.5)$ & \\
\hline Traditional pit & $74(42.1)$ & $5(41.7)$ & $75(49.7)$ & $36(45.0)$ & $5(62.5)$ & \\
\hline Ventilated improved pit & $74(42.1)$ & $3(25.0)$ & $48(38.4)$ & $32(40.0)$ & $2(25.0)$ & \\
\hline Bush, field, other & $4(2.3)$ & $1(8.3)$ & 5 (3.3) & $3(3.8)$ & $0(0.0)$ & \\
\hline Water Source & & & & & & 0.425 \\
\hline Bore hole & $30(17.1)$ & $0(0.0)$ & $29(19.2)$ & $10(12.7)$ & $0(0.0)$ & \\
\hline Surface & $103(58.5)$ & $8(66.7)$ & $84(55.6)$ & $52(65.8)$ & $4(50.0)$ & \\
\hline Rain water & $11(6.3)$ & $1(8.3)$ & $9(6.0)$ & $2(2.5)$ & $0(0.0)$ & \\
\hline Pipe in house & 32 (18.2) & $3(25.0)$ & $29(19.2)$ & $15(19.0)$ & $4(50.0)$ & \\
\hline Source of Light & & & & & & 0.385 \\
\hline Electricity & $47(26.7)$ & $3(25.0)$ & $25(16.6)$ & $19(23.8)$ & $1(12.5)$ & \\
\hline Kerosene & $67(38.1)$ & $6(50.0)$ & $60(39.7)$ & $33(41.2)$ & $4(50.0)$ & \\
\hline Tin lamp & $20(11.4)$ & $0(0.0)$ & $23(15.2)$ & $16(20.0)$ & $1(12.5)$ & \\
\hline Solar & $36(20.5)$ & $3(25.0)$ & $32(21.2)$ & $9(11.3)$ & $2(25.0)$ & \\
\hline Other & $6(3.4)$ & $0(0.0)$ & $11(7.3)$ & $3(3.7)$ & $0(0.0)$ & \\
\hline Has television in home & $48(27.3)$ & $3(25.0)$ & $26(17.2)$ & $22(27.5)$ & $4(50.0)$ & 0.062 \\
\hline Body mass index, median (IQR) & $21.6(20.1-23.5)$ & $21.1(18.7-22.8)$ & $21.2(19.7-23.0)$ & $22.2(20.8-23.5)$ & $21.1(19.2-22.2)$ & 0.094 \\
\hline Body mass index, category & & & & & & 0.777 \\
\hline Underweight $(<18)$ & $8(4.6)$ & $0(0)$ & $13(8.7)$ & $4(4.9)$ & $0(0.0)$ & \\
\hline Normal (18-25) & $143(82.2)$ & $10(83.3)$ & $121(80.7)$ & $65(80.3)$ & $8(100)$ & \\
\hline Overweight or obese $(>25)^{2}$ & $23(13.2)$ & $2(16.7)$ & $16(10.7)$ & $12(14.8)$ & $0(0.0)$ & \\
\hline School & & & & & & 0.346 \\
\hline$A$ & $52(29.4)$ & $2(16.7)$ & $36(23.5)$ & $21(25.9)$ & $4(50.0)$ & \\
\hline $\mathrm{B}$ & $16(9.0)$ & $2(16.7)$ & $11(7.2)$ & $10(12.4)$ & $1(12.5)$ & \\
\hline $\mathrm{C}$ & $26(14.7)$ & $1(8.3)$ & $19(12.4)$ & $19(23.5)$ & $0(0.0)$ & \\
\hline $\mathrm{D}$ & $42(23.7)$ & $2(16.7)$ & $34(22.2)$ & $14(17.3)$ & $2(25.0)$ & \\
\hline$E$ & $20(11.3)$ & $2(16.7)$ & $25(16.3)$ & $11(13.6)$ & $1(12.5)$ & \\
\hline $\mathrm{F}$ & $21(11.9)$ & $3(25.0)$ & $28(18.3)$ & $6(7.4)$ & $0(0.0)$ & \\
\hline Any antibiotic use past 30 days & $36(20.7)$ & $1(8.3)$ & $28(18.8)$ & $17(21.5)$ & $2(25.0)$ & 0.847 \\
\hline \multicolumn{7}{|l|}{ Menstruation \& Management } \\
\hline $\begin{array}{l}\text { Median age in years at first period } \\
(\mathrm{IQR})\end{array}$ & $14(14-15)$ & $14(14-15)$ & $14(14-15)$ & $14(14-15)$ & $15(14-15)$ & 0.510 \\
\hline $\begin{array}{l}\text { Early menarche (first period }<13 \\
\text { years of age) }\end{array}$ & $5(3.0)$ & $0(0.0)$ & $10(6.9)$ & $3(3.7)$ & $0(0)$ & 0.498 \\
\hline $\begin{array}{l}\text { Cloth used to manage last menstrual } \\
\text { period }\end{array}$ & $34(19.3)$ & $3(25.0)$ & $44(29.1)$ & $25(31.3)$ & $1(12.5)$ & 0.143 \\
\hline \multicolumn{7}{|l|}{ Period Characteristics } \\
\hline Pain or cramps last period & $106(60.2)$ & $6(50.0)$ & $106(70.2)$ & $47(58.8)$ & 7 (87.5) & 0.114 \\
\hline Menstrual bleeding last period & & & & & & 0.055 \\
\hline Light & $11(6.2)$ & $2(16.7)$ & $7(4.6)$ & $9(11.3)$ & $2(25.0)$ & \\
\hline Normal & $139(79.0)$ & $10(83.3)$ & $110(72.9)$ & $59(73.7)$ & $5(62.5)$ & \\
\hline Heavy & $26(15.8)$ & $0(0.0)$ & $34(22.5)$ & $12(15.0)$ & $1(12.5)$ & \\
\hline Median days of last period (IQR) & $4(3-5)$ & $4(3-4.75)$ & $4(3-5)$ & $4(3-5)$ & $4.5(3-5.75)$ & 0.149 \\
\hline 1-3 days & $70(40.0)$ & $5(41.7)$ & $46(30.7)$ & $25(31.7)$ & $3(37.5)$ & 0.341 \\
\hline 4-6 days & $93(53.1)$ & $5(41.7)$ & $92(61.3)$ & $43(54.5)$ & $5(62.5)$ & \\
\hline $7+$ days & 12 (6.9) & 2 (16.6) & 12 (8.0) & $11(13.9)$ & $0(0.0)$ & \\
\hline
\end{tabular}

${ }^{1}$ Excludes $n=4$ participants with $<5,000$ total sequence reads.

${ }^{2} \mathrm{BMI}$ category "overweight or obese" includes $n=4$ participants with $B M I>30$.

${ }^{3} P$-value by chi-square test unless otherwise noted; Fisher exact test used for categorical comparisons where any cell count was less than 5.

${ }^{4}$ Wilcoxon rank sum test used for comparison of non-normally distributed continuous variables. 


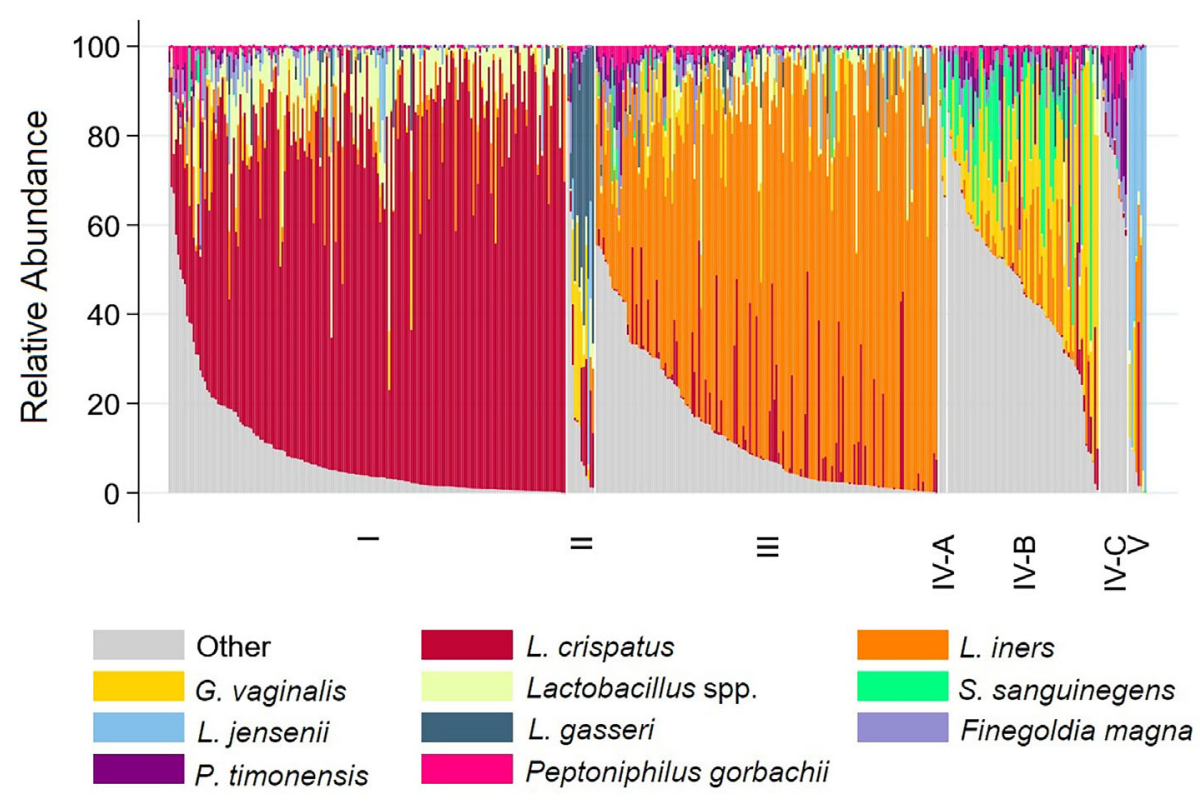

FIGURE 1 Stacked bar chart showing relative abundance of 10 taxa with highest mean relative abundance by community state type for each participant. Legend: The relative abundance of the 10 taxa with the highest mean relative abundance is shown ( $\mathrm{y}$-axis), with individual subjects represented by individual bars ( $\mathrm{N}=431$ ), separated by Community State Type (x-axis).

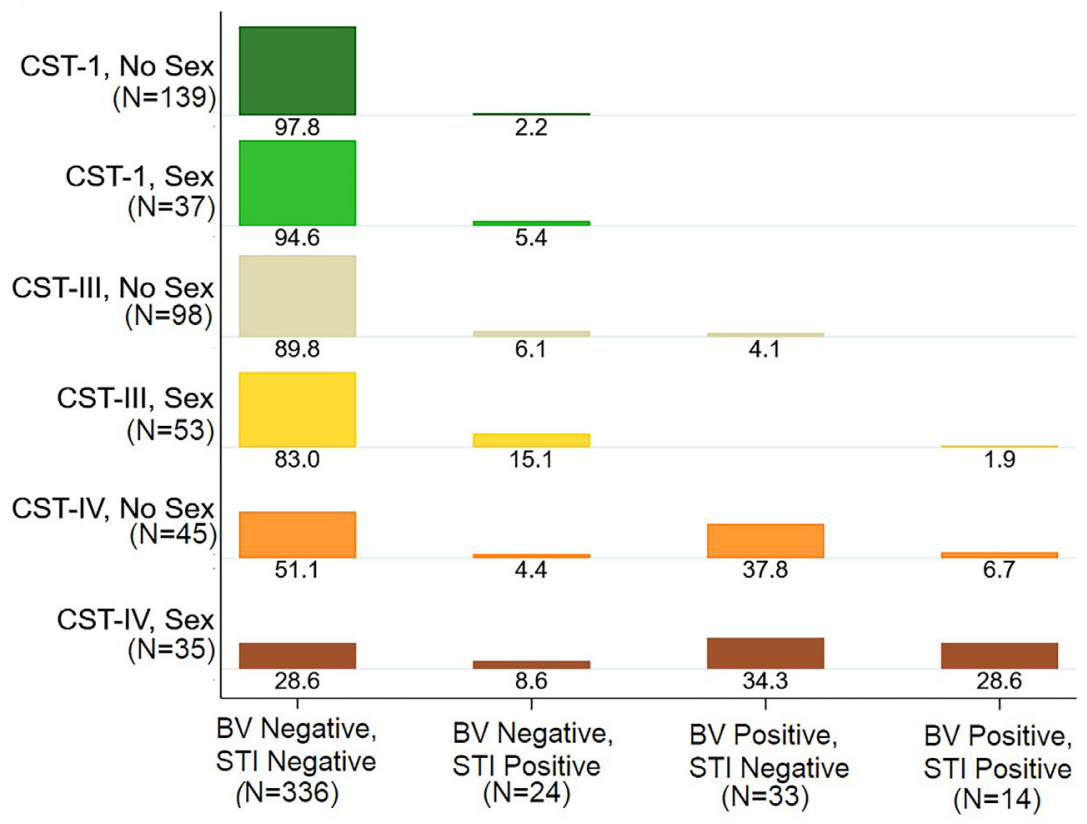

FIGURE 2 | Distribution of Bacterial vaginosis (BV) and Sexually Transmitted Infection (STI) Status by Vaginal Microbiome Community State Type (CST), Stratified by Sexual Activity. Legend: The plot shows the distribution of BV and STI status by vaginal CST, stratified by sexual activity ever. For example, among girls with CST-I who do not report sexual activity, 97.8\% were negative for BV and STI and 2.2\% were BV Negative and STI positive. Among girls with CST-IV who reported having sexual activity, $28.6 \%$ were negative for BV and STI, 8.6\% with STI only, 34.3\% with BV only, and 28.6\% with both BV and STI. 


\section{A Non-metric multidimensional scaling plot}

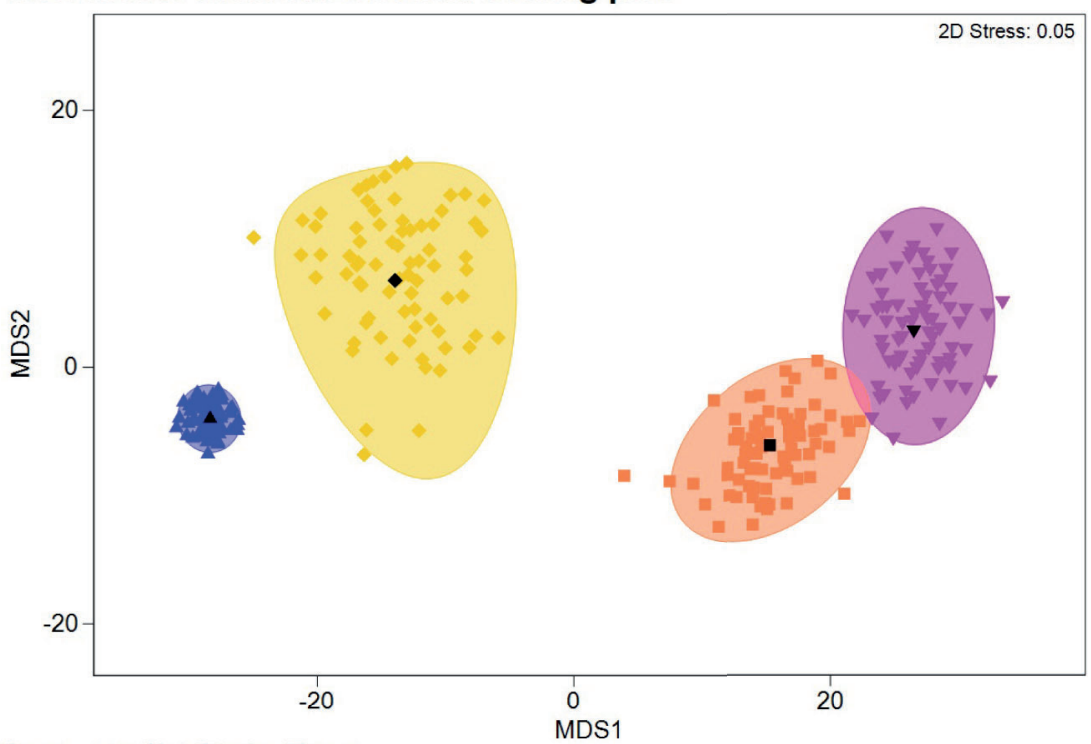

\section{B Community State Type}

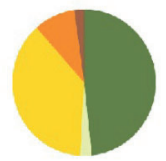

CST-I

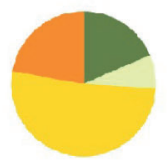

CST-II
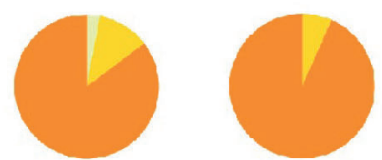

CST-III
CST-V

\section{c Taxa Relative Abundance}
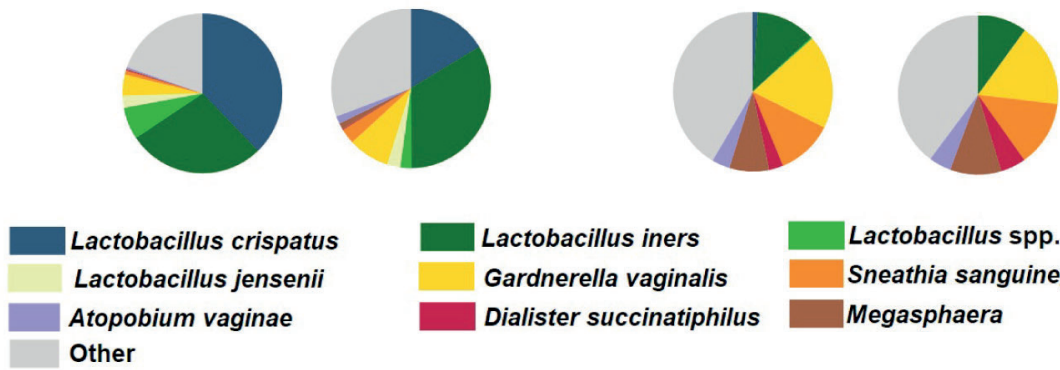

Lactobacillus spp.

Sneathia sanguinegens

Megasphaera

FIGURE 3 | Non-metric dimensional scaling plot for each of the four outcome states for Bacterial vaginosis (BV) or sexually transmitted infection (STI) and distribution of Community State Type (CST) and taxa relative abundance. (A) The four different colors represent the four outcome states for Bacterial vaginosis and sexually transmitted infection. STI is a composite of infection with any of C. trachomatis, N. gonorrhoeae, T. vaginalis. Blue = negative for BV and all STIs; yellow = STI positive, BV negative; orange = BV positive, STI negative; pink = both STI and BV positive. Each colored mark indicates one of 100 bootstrappings of the dataset. The matching shaded area represents the 95\% coverage. The black symbol at the center of each colored shape represents the average centroid of the 100 bootstraps. (B) Pie charts below the non-metric dimensional scaling plot show the distribution of CST, aligned to outcome states for BV and STI (N=431 individuals represented). (C) Pie charts below the non-metric dimensional scaling plot show the distribution of mean relative abundance of taxa identified through stability selection in association with BV and STI ( $\mathrm{N}=431$ individuals represented).

protective of $\mathrm{BV}(\mathrm{aPRR}=0.76 ; 95 \% \mathrm{CI}: 0.60-0.97)$. In a multivariable log-binomial regression model simultaneously adjusted for all variables presented, only age ( $\mathrm{aPRR}=1.23 ; 95 \%$ CI: $1.04-1.46$ ) and sexual intercourse (aPRR=3.11; 95\% CI: 1.10 8.77) were statistically significantly associated with STI (Table 6). While higher BMI was associated with lower likelihood of STI, this became insignificant once adjusted for age due to the positive correlation between BMI and age.

\section{DISCUSSION}

The major findings in our analyses are: (1) L. crispatus dominant CST-I was the most common vaginal community state type, and was more likely among girls who did not report sexual activity. (2) Girls who used cloth to manage their menses were more likely to have CST-III or non-optimal CST-IV than CST-I. (3) The prevalence of BV and STIs was high. 
TABLE 3 | Results of stability selection with $p=0.20$ Error Bound.

Bacterial Vaginosis (BV)

\begin{tabular}{|c|c|c|c|c|c|c|c|}
\hline \multirow[t]{2}{*}{ Taxa } & \multirow{2}{*}{$\begin{array}{l}\text { Proportion of Bootstrap } \\
\text { samples Identified in }\end{array}$} & \multicolumn{2}{|c|}{ Mean Relative Abundance } & \multirow[t]{2}{*}{ Taxa } & \multirow{2}{*}{$\begin{array}{l}\text { Proportion of Bootstrap } \\
\text { samples Identified in }\end{array}$} & \multicolumn{2}{|c|}{ Mean Relative Abundance } \\
\hline & & $\begin{array}{l}\text { BV present } \\
\% \text { (SD) }\end{array}$ & $\begin{array}{l}\text { BV Absent } \\
\% \text { (SD) }\end{array}$ & & & $\begin{array}{c}\mathrm{STI} \% \\
\text { present (SD) }\end{array}$ & $\begin{array}{c}\text { STI\% } \\
\text { absent (SD) }\end{array}$ \\
\hline $\begin{array}{l}\text { Lactobacillus } \\
\text { jensenii }\end{array}$ & 0.840 & $0(0)$ & $2.50(10.6)$ & Megasphaera & 0.612 & $4.43(6.83)$ & $0.86(3.32)$ \\
\hline $\begin{array}{l}\text { Sneathia } \\
\text { sanguinegens }\end{array}$ & 0.918 & $12.0(11.0)$ & $0.96(5.2)$ & $\begin{array}{l}\text { Atopobium } \\
\text { vaginae }\end{array}$ & 0.762 & $2.59(4.37)$ & $0.63(2.66)$ \\
\hline $\begin{array}{l}\text { Dialister } \\
\text { succinatiphilus }\end{array}$ & 0.920 & $3.55(3.15)$ & $0.20(0.89)$ & $\begin{array}{l}\text { S. } \\
\text { sanguinegens }\end{array}$ & 0.828 & $6.64(8.45)$ & $1.72(6.73)$ \\
\hline $\begin{array}{l}\text { Lactobacillus } \\
\text { spp. }\end{array}$ & 0.996 & $0.19(0.61)$ & $6.14(7.99)$ & L. crispatus & 0.958 & $10.68(24.7)$ & $34.6(36.9)$ \\
\hline Megasphaera & 0.998 & 8.78 (7.28) & 0.25 (1.64) & & & & \\
\hline
\end{tabular}

Sexually Transmitted Infection (STI)
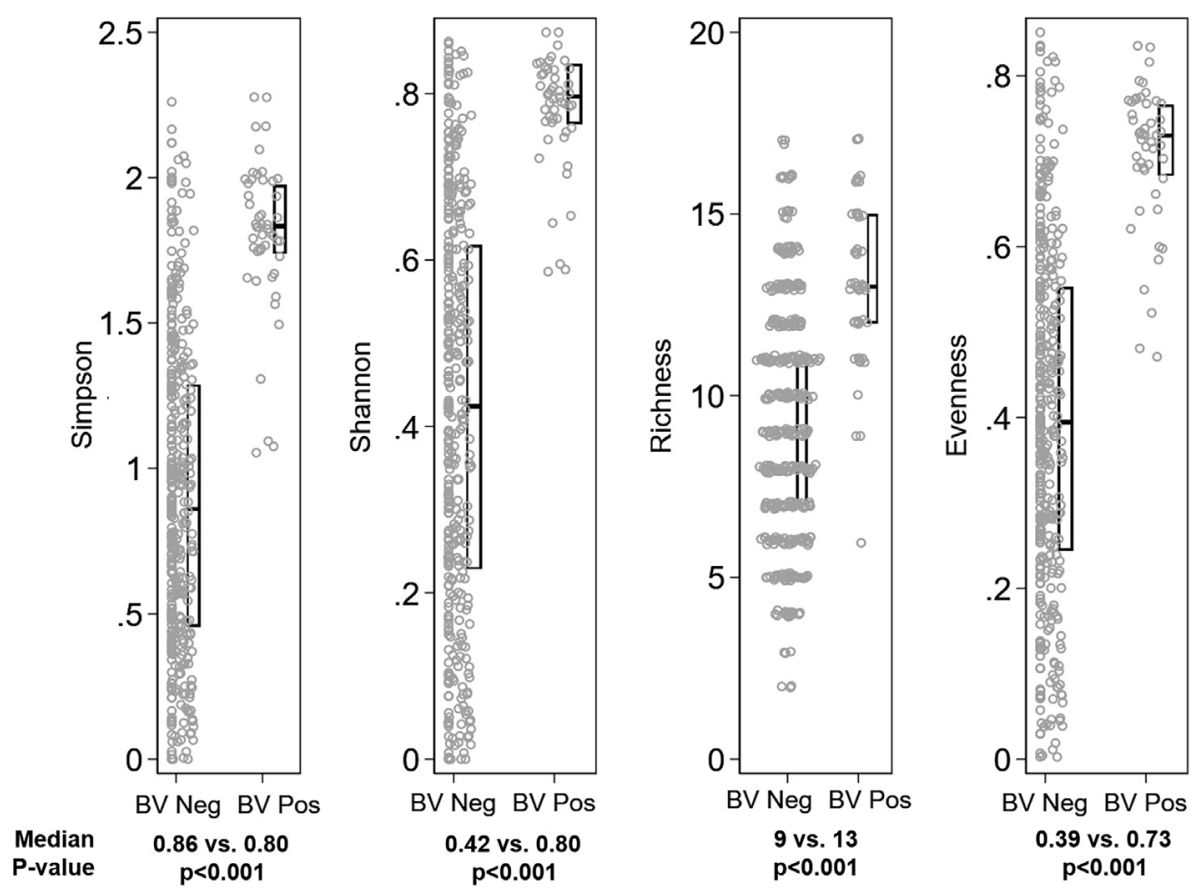

FIGURE 4 | Distribution of alpha diversity metrics by Bacterial vaginosis (BV) status. Legend: The distribution of alpha diversity metrics (Simpson, Shannon, Richness, and Evenness) are shown on the y-axis, separately for girls with Nugent score 0-6 ("BV Neg", N=382) and Nugent score 7-10 ("BV Pos", N=49) on the xaxis. Within panels, each grey dot represents a single observation. Box plots indicate the median (horizontal bar) and interquartile range (lower $25^{\text {th }}$ percentile and upper $75^{\text {th }}$ percentile). Below each graph, the median value for each alpha diversity metric is reported for "BV Neg" and "BV Pos" observations, with Wilcoxon rank sum $p$-value of the comparison reported beneath the medians.

The majority of girls had a L. crispatus (41\%) or L. iners (35\%) dominant vaginal CST. This is important because numerous studies show that women of African descent are more likely to have non-optimal CST-IV vaginal community type (Ravel et al., 2011; Lewis et al., 2017). In our study of adult women (median age 23 years) in long-term sexual relationships who resided in Kisumu (approximately $70 \mathrm{~km}$ from Siaya County), at baseline
8.7\% had L. crispatus dominant CST-I, $42 \%$ had L. iners dominant CST-III, and $47.2 \%$ had non-optimal CST-IV (Mehta et al., 2020). That such a high proportion of native Kenyan adolescent girls in our current study had L. crispatus dominant CST-I clearly indicates that this is a common phenotype and is most likely altered as girls become sexually active, as reflected by the increased odds of association with CST- 

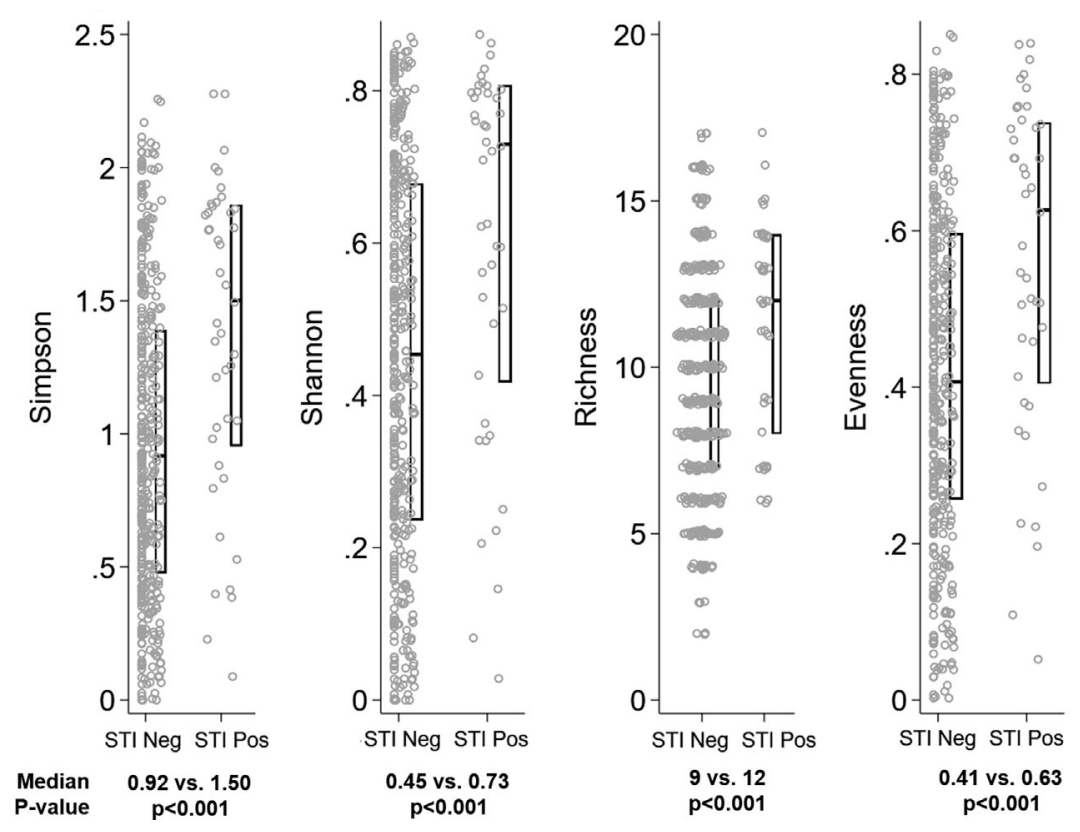

FIGURE 5 | Distribution of alpha diversity metrics by Sexually Transmitted Infection (STI) status. Legend: The distribution of alpha diversity metrics (Simpson, Shannon, Richness, and Evenness) are shown on the y-axis, separately for girls testing negative for all three STIs ("STI Neg", N=43) and testing positive for any STI ("STI Pos", N=388) on the x-axis. Within panels, each grey dot represents a single observation. Box plots indicate the median (horizontal bar) and interquartile range (lower $25^{\text {th }}$ percentile and upper $75^{\text {th }}$ percentile). Below each graph, the median value for each alpha diversity metric is reported for "STI Neg" and "STI Pos" observations, with Wilcoxon rank sum p-value of the comparison reported beneath the medians.

TABLE 4 | Results of multivariable adjusted multinomial logistic regression with random effect for school: factors associated with community state type, N=420.

\begin{tabular}{|c|c|c|c|c|}
\hline & $\begin{array}{c}\text { CST-II (vs. CST-I) OR } \\
(95 \% \mathrm{Cl})\end{array}$ & $\begin{array}{l}\text { CST-III (vS. CST-I) OR } \\
(95 \% \mathrm{CI})\end{array}$ & $\begin{array}{l}\text { CST-IV (vS. CST-I) OR } \\
(95 \% \mathrm{CI})\end{array}$ & $\begin{array}{c}\text { CST-V (vs. CST-I) OR } \\
(95 \% \mathrm{Cl})\end{array}$ \\
\hline Age in years, continuous & $1.04(0.66-1.63)$ & $1.01(0.87-1.17)$ & $1.19(1.02-1.38)^{b}$ & $1.26(0.83-1.92)$ \\
\hline Household amenities score, continuous & $1.14(0.73-1.79)$ & $0.71(0.56-0.90)^{\mathrm{a}}$ & $0.90(0.69-1.19)$ & $1.07(0.55-2.10)$ \\
\hline $\begin{array}{l}\text { Ever had sex, willingly and/or forced or tricked (vs. } \\
\text { Never) }\end{array}$ & $1.18(0.19-7.36)$ & $2.00(1.63-2.45)^{a}$ & $2.58(1.14-5.86)^{b}$ & $0.49(0.02-10.1)$ \\
\hline Cloth used during last period (vs. no) & $1.51(0.63-3.60)$ & $1.59(1.17-2.17)^{\mathrm{a}}$ & $1.72(1.03-2.86)^{b}$ & $0.72(0.11-4.60)$ \\
\hline Body mass index, continuous & $0.91(0.67-1.25)$ & $0.93(0.86-1.01)^{c}$ & $1.02(0.94-1.11)$ & $0.82(0.70-0.98)^{b}$ \\
\hline
\end{tabular}

${ }^{a} p$-value $<0.01$.

${ }^{b} 0.01<p$-value $<0.05$.

${ }^{c} 0.05<p$-value $<0.10$.

III (aOR 2.00) and CST-IV (aOR=2.58) compared to CST-I for girls ever having had sexual exposure, adjusted for age, socioeconomic measure, and cloth use for menses. The association between older age and CST-III and CST-IV may represent that older girls have different types of sex partners, different sexual practices, or may have been sexually active longer. As the cohort is ongoing, our eventual longitudinal evaluation will be able to quantify this change over time as girls become sexually active, and among those becoming sexually active we will be able to examine the association with sexual practices and partner characteristics.

This finding has implications for the design of behavioral and biological interventions, indicating that a non-optimal
VMB composition may be preventable and that adolescence could be a critical intervention point for preventing adverse reproductive health outcomes. Poor quality menstrual hygiene is modifiable, through provision of cheap accessible hygienic products instead of cloth use, and could have substantial biological consequence. Cloth use may promote non-optimal vaginal microbiome through facilitation of anaerobic bacterial growth, through improperly washed fabric (i.e., direct transfer of bacteria), or an occlusive environment. In a district level household survey of 577,758 women aged 15-49 years in India, those who used cloth during menses were more likely to report vaginal discharge in the past 3 months $(\mathrm{aOR}=1.30)$, adjusted for age, gynecologic factors, and socioeconomic indicators 


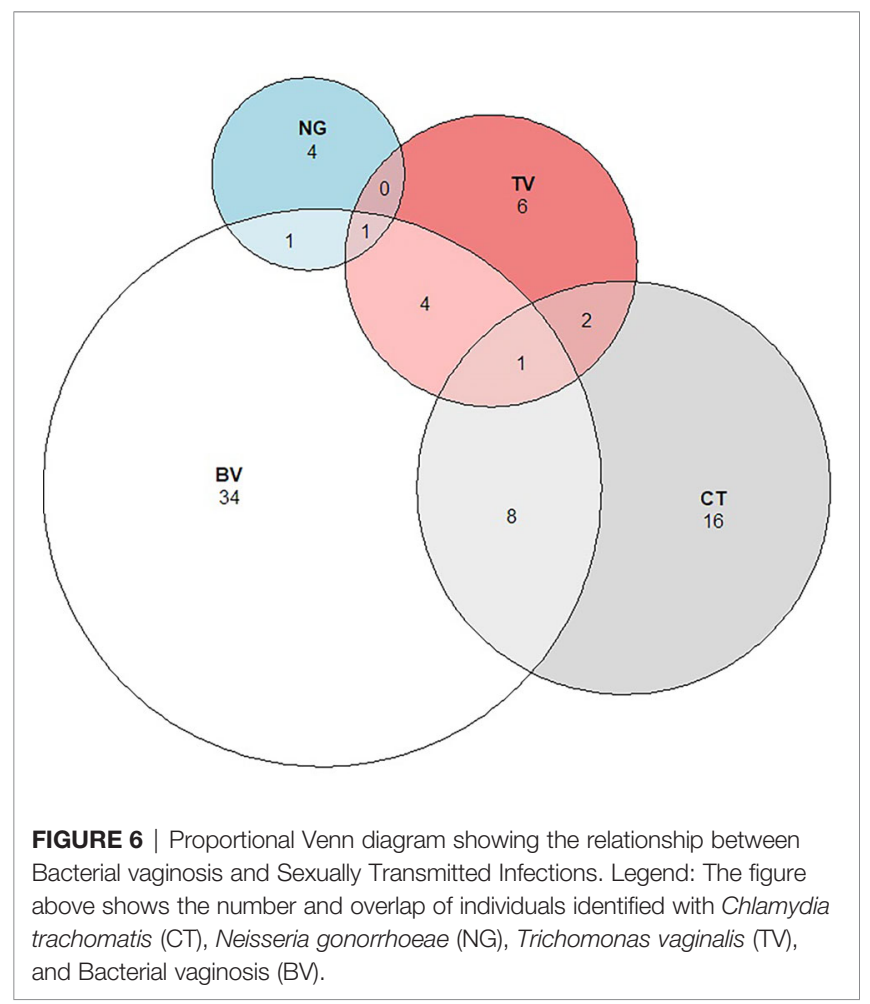

TABLE 5 | Results of poisson regression with robust variance estimate and random effect for school: crude and multivariable adjusted associations of sociodemographic and behavioral factors with bacterial vaginosis.

\begin{tabular}{|c|c|c|}
\hline Variables & $\begin{array}{c}\text { Crude } \\
\text { Prevalence } \\
\text { Rate Ratio } \\
{[95 \% \mathrm{Cl}]}\end{array}$ & $\begin{array}{c}\text { Adjusted } \\
\text { Prevalence } \\
\text { Rate Ratio } \\
{[95 \% \mathrm{Cl}]} \\
\mathrm{N}=423\end{array}$ \\
\hline Age in year & $1.40[1.26-1.55]$ & $1.24[1.15-1.33]$ \\
\hline Household amenities score, continuous & $0.78[0.60-1.02]$ & $0.76[0.60-0.97]$ \\
\hline $\begin{array}{l}\text { Ever had sex, willingly and/or forced or } \\
\text { tricked }\end{array}$ & $2.32[1.47-3.65]$ & $2.17[1.41-3.35]$ \\
\hline Body mass index, continuous & $1.15[1.10-1.21]$ & $1.13[1.11-1.15]$ \\
\hline Cloth used to manage last menstrual period & $1.21[0.78-1.86]$ & \\
\hline
\end{tabular}

Multivariable model simultaneously adjusted for all variables presented.

(Anand et al., 2015). Cloth use for menses has also been associated with BV among women in Tanzania (Baisley et al., 2009) and in India (Torondel et al., 2018), and tampon use has been associated with VMB composition among women in the United States (Noyes et al., 2018). Alterations in vaginal flora during menses may be modified with other MHM products such as the menstrual cup. Menstrual cups are medical grade silicone bell chambers inserted vaginally to collected menstrual flow. Among 406 U.S. women having 4,750 collective days of menstrual cup use, colonization with Lactobacillus was maintained at pre-cup use levels with no change in $\mathrm{pH}$ or colonization with S. aureus, G. vaginalis, or Bacteroides spp (North and Oldham, 2011). Systematic review with metaanalysis suggests that menstrual cups are a safe option for
TABLE 6 | Results of poisson regression with robust variance estimate and random effect for school: crude and multivariable adjusted associations of sociodemographic and behavioral factors with non-ulcerative sexually transmitted infection.

\begin{tabular}{|c|c|c|}
\hline Variables & $\begin{array}{c}\text { Crude } \\
\text { Prevalence } \\
\text { Rate Ratio } \\
{[95 \% \mathrm{Cl}]}\end{array}$ & $\begin{array}{c}\text { Adjusted } \\
\text { Prevalence } \\
\text { Rate Ratio } \\
{[95 \% \mathrm{Cl}]} \\
\mathrm{N}=431\end{array}$ \\
\hline Age in years, continuous & $1.35[1.12-1.61]$ & $1.23[1.04-1.46]$ \\
\hline Household amenities score, continuous & $0.91[0.74-1.12]$ & \\
\hline $\begin{array}{l}\text { Ever had sex, willingly and/or forced or } \\
\text { tricked }\end{array}$ & $3.62[1.21-10.8]$ & $3.11[1.10-8.77]$ \\
\hline $\begin{array}{l}\text { Early menarche (first period before age } 13 \\
\text { years) }\end{array}$ & $3.59[1.92-6.70]$ & \\
\hline \multicolumn{3}{|l|}{ Body mass index, category } \\
\hline Underweight (<18) & ref & \\
\hline Normal (18-25) & $0.41[0.23-0.73]$ & \\
\hline Overweight or obese (>25) & $0.66[0.22-1.97]$ & \\
\hline
\end{tabular}

menstrual hygiene in low-, middle-, and high-income countries (van Eijk et al., 2019). In a cluster randomized controlled feasibility study of 644 girls aged 14-16 years old, PhillipsHoward et al. randomized girls by school cluster 1:1:1 to reusable menstrual cups, disposable sanitary pads, or standard water, sanitation and hygiene counseling (PhillipsHoward et al., 2016). The prevalence of BV (Gram stain Nugent score $7-10)$ was reduced by $35 \%(\mathrm{aPRR}=0.65 ; \mathrm{p}=0.034)$ for menstrual cup users (13\%) compared to pad users (20\%) and control subjects (19\%). Menstrual cup use also resulted in 52\% $(\mathrm{p}=0.039)$ reduction in the prevalence of STIs (composite measure of $N$. gonorrhoeae, C. trachomatis, T. vaginalis). In our current analysis, cloth use was more common among girls with BV (29.2\%) than without BV (24.5\%), and for girls with STI (31.7\%) than without STI (24.4\%), though neither difference was statistically significant. However, cloth use was significantly associated with CSTI-III $(\mathrm{aOR}=1.59)$ and CST-IV $(\mathrm{aOR}=1.72)$. While this may seem contradictory, this could reflect underreporting of cloth use, which could have attenuating effects on the measure of association with $\mathrm{BV}$ and STI, both having smaller sample size than CST-III and CST-IV. Of note, vaginal discharge was more commonly reported by girls using cloth $(28.7 \%)$ than those without (21.1\%), though not statistically significant ( $\mathrm{p}=0.10$; data not shown).

The prevalence of BV and STIs was high, with $9.9 \%$ of girls having STIs and $11.2 \%$ having BV. While BV is considered a sexually enhanced condition (Verstraelen et al., 2010), there are non-sexual risk factors including intravaginal and vaginal hygiene practices (Low et al., 2011), cigarette smoking (Nelson et al., 2018), and male sexual partner's circumcision status (Liu et al., 2015). Of girls who reported ever having had sexual activity, $37 \%$ reported not knowing the male partner's circumcision status and just 3\% reported the male partner as uncircumcised [it is estimated that $40 \%$ of men in Siaya County are uncircumcised (McKinnon et al., 2019)], precluding meaningful analysis of this variable. Only one girl reported smoking cigarettes. It is a limitation that we did not ask about 
intravaginal practices or application of substances to the vagina as it was felt by the local study team to be too invasive and that girls would not answer due to perceived stigma. Among girls who reported they had ever had sexual activity, we did not find factors that differentiated girls with BV or STI, though this analysis was biased by underreporting of sexual activity, as evidenced by $39 \%$ of girls with STI reporting never having been sexually active. Antibiotic use within the past 30 days was common (20\%), and we did not find an association between recent antibiotic use and BV, STI, or CST. This may be due to misclassification (e.g., taking anti-malarial and reporting it as antibiotic use), underreporting of antibiotics, use of antibiotics class, dose, or duration that was not strongly influential to the $\mathrm{VMB}$, or because the sample represented a mixture of antibiotic classes and indications, and therefore too much noise to detect a signal.

The VMB composition differed substantially by BV and/or STI status, as demonstrated by global community comparison (ANOSIM), distribution of CSTs, and distribution of specific taxa. These differences were in keeping with previous literature. Of note, G. vaginalis was not identified by ElasticNet implemented within stability selection as one of the specific taxa discriminating between BV and STI states, though it is considered a key taxa in BV pathogenesis (Schwebke et al., 2014) and was one of the top taxa by contribution to Bray Curtis dissimilarity analysis. Differences in results by machine learning and ecological approaches highlight the importance of using different analytic approaches to maximize information gain and robustness.

\section{Limitations}

There was substantial underreporting of sexual activity, as 39\% of STIs occurred among girls who reported never having had sexual activity (willing or forced). Having a small number of girls infected with each STI, we analyzed STI as a composite of CT, NG, and TV; while data comparing the VMB composition by each pathogen are limited, the specific taxa associated with each pathogen may differ (Masha et al., 2019). Nevertheless, despite high co-infection of BV and STIs, we demonstrate that taxa associated with STIs differ from those associated with $\mathrm{BV}$ and longitudinal analyses will provide insight on the temporal occurrence of BV and/or STIs, and VMB composition and taxa in relation to specific STI pathogens. HIV prevalence at baseline was $1.4 \%$, and while this is high given the young median age of girls, the number is small and we cannot relate HIV status to VMB in this analysis. Our results may not be generalizable to girls who are not in school. In this cross-sectional analysis of baseline data, we cannot be certain that exposures preceded outcomes.

\section{CONCLUSIONS}

Nearly half of adolescent girls had a L. crispatus dominant VMB, differing substantially from studies of young adult and adult women in Kenya and other parts of sub-Saharan Africa. This indicates that non-optimal VMB may be an acquired state for many women and girls, and interventions to maintain or reconstitute $L$. crispatus dominance should be considered, with adolescence being a potentially critical point. Menstrual cups may be a potential intervention for preventing non-optimal vaginal microbiome composition associated with non-hygienic menstrual management.

\section{DATA AVAILABILITY STATEMENT}

The datasets presented in this study can be found in online repositories. The names of the repository/repositories and accession number(s) can be found below: https://www.ncbi. nlm.nih.gov/bioproject/PRJNA540529.

\section{ETHICS STATEMENT}

This study was approved by the institutional review boards of the Kenya Medical Research Institutes (KEMRI, SERU \#3215), Liverpool School of Tropical Medicine (LSTM, \#15-005), and University of Illinois at Chicago (UIC, \#2017-1301). Written informed consent to participate in this study was provided by the participants' legal guardian/next of kin.

\section{AUTHOR CONTRIBUTIONS}

SM: Obtained funding, study conceptualization and design, statistical analysis inference, data visualization, drafted manuscript. GZ: Study oversight and management to ensure integrity to protocols and integration of $\mathrm{CaCHe}$ within CCG trial, data management and cleaning, critical review and revision of manuscript. FO: Study oversight and management to ensure integrity to protocols of $\mathrm{CaCHe}$, critical review and revision of manuscript. EN: Study oversight and management to ensure integrity to protocols of CCG trial, critical review and revision of manuscript. WA: Development, implementation, and oversight of laboratory protocols in Kenya, acquisition of data, microbiologic analyses and interpretation, critical review and revision of manuscript. RB: Design and execution of statistical analysis approaches, critical review and revision of manuscript. SG: Development and oversight of protocols for amplicon sequencing, microbiologic analyses and interpretation, critical review and revision of manuscript. AE: Data management and cleaning, critical review and revision of manuscript. DK: Study oversight and management to ensure integrity to protocols of CCG trial and regulatory integration of $\mathrm{CaCHe}$, critical review and revision of manuscript. PP-H: Obtained funding, study oversight and management to ensure integrity to protocols, critical review and revision of manuscript. All authors contributed to the article and approved the submitted version. 


\section{FUNDING}

This study was supported by grant number R01-HD093780 (PI: Mehta) from the National Institutes of Health, Eunice Shriver National Institute of Child Health and Human Development, and the Joint Global Health Trials Initiative (UK-Medical Research Council/ Department for International Development/ Wellcome Trust/Department of Health and Social Care, grant MR/N006046/1, PI: Phillips-Howard). The funders have no role in the design of the study, the collection, analysis, and interpretation of data, or in writing the manuscript.

\section{REFERENCES}

Amornkul, P. N., Vandenhoudt, H., Nasokho, P., Odhiambo, F., Mwaengo, D., Hightower, A., et al. (2009). HIV Prevalence and Associated Risk Factors Among Individuals Aged 13-34 Years in Rural Western Kenya. PloS One 4 (7), e6470. doi: 10.1371/journal.pone.0006470

Anand, E., Singh, J., and Unisa, S. (2015). Menstrual Hygiene Practices and its Association With Reproductive Tract Infections and Abnormal Vaginal Discharge Among Women in India. Sexual Reprod. Health Care 6 (4), 249254. doi: 10.1016/j.srhc.2015.06.001

Atashili, J., Poole, C., Ndumbe, P. M., Adimora, A. A., and Smith, J. S. (2008). Bacterial Vaginosis and HIV Acquisition: A Meta-Analysis of Published Studies. AIDS 22, 1493-1501. doi: 10.1097/QAD.0b013e3283021a37

Baisley, K., Changalucha, J., Weiss, H. A., Mugeye, K., Everett, D., Hambleton, I., et al. (2009). Bacterial Vaginosis in Female Facility Workers in North-Western Tanzania: Prevalence and Risk Factors. Sex Transm Infect. 85, 370-375. doi: 10.1136/sti.2008.035543

Barros, A. J. D., and Hirakata, V. N. (2003). Alternatives for Logistic Regression in Cross-Sectional Studies: An Empirical Comparison of Models That Directly Estimate the Prevalence Ratio. BMC Med. Res. Methodol 3, 21. doi: 10.1186/ 1471-2288-3-21

Blum, R. W., and Nelson-Mmari, K. (2004). The Health of Young People in a Global Context. J. Adolesc. Health 35, 402-418. doi: 10.1016/S1054-139X(03)00537-8

Borgdorff, M. W., Kwaro, D., Obor, D., Otieno, G., Kamire, V., Odongo, F., et al. (2018). HIV Incidence in Western Kenya During Scale-Up of Antiretroviral Therapy and Voluntary Medical Male Circumcision: A Population-Based Cohort Analysis. Lancet HIV 5, e241-e249. doi: 10.1016/S2352-3018(18)30025-0

British Association of Sexual Health and HIV. (2021). Available at: https://www. bashhguidelines.org/current-guidelines/vaginal-discharge/bacterial-vaginosis2012/ (Accessed March 22, 2021).

Centers for Disease Control and Prevention. (2015). Sexually Transmitted Diseases Treatment Guidelines. Available at: https://www.cdc.gov/std/treatmentguidelines/bv.htm (Accessed August 16, 2021).

Clarke, K. R. (1993). Non-Parametric Multivariate Analyses of Changes in Community Structure. Austral J. Ecol. 18 (1), 117-143. doi: 10.1111/j.1442-9993.1993.tb00438.x

Eschenbach, D. A., Gravett, M. G., Chen, K. C., Hoyme, U. B., and Holmes, K. K. (1984). Bacterial Vaginosis During Pregnancy. An Association With Prematurity and Postpartum Complications. Scand. J. Urol Nephrol. Suppl. 86, 213-222

France, M., Ma, B., Gajer, P., Brown, S., Humphrys, M. S., Holm, J. B., et al. (2020). VALENCIA: A Nearest Centroid Classification Method for Vaginal Microbial Communities Based on Composition. Microbiome 8, 166. doi: 10.1186/s40168020-00934-6

Gihring, T. M., Green, S. J., and Schadt, C. W. (2012). Massively Parallel rRNA Gene Sequencing Exacerbates the Potential for Biased Community Diversity Comparisons Due to Variable Library Sizes. Environ. Microbiol. 14 (2), 285290. doi: 10.1111/j.1462-2920.2011.02550.x

Hay, P. E., Lamont, R. F., Taylor-Robinson, D., Morgan, D. J., Ison, C., and Pearson, J. (1994). Abnormal Bacterial Colonisation of the Genital Tract and Subsequent Preterm Delivery and Late Miscarriage. BMJ 308, 295-298. doi: 10.1136/bmj.308.6924.295

Hintze, J. (2014). PASS 15. NCSS, LLC (Kaysville, Utah, USA). Available at: http:// www.ncss.com.

\section{ACKNOWLEDGMENTS}

This paper is published with the permission of KEMRI Director.

\section{SUPPLEMENTARY MATERIAL}

The Supplementary Material for this article can be found online at: https://www.frontiersin.org/articles/10.3389/fcimb.2021. 716537/full\#supplementary-material

Holm, J. B., Humphrys, M. S., Robinson, C. K., Settles, M. L., Ott, S., Fu, L., et al. (2019). Ultrahigh-Throughput Multiplexing and Sequencing of $>500$-BasePair Amplicon Regions on the Illumina HiSeq 2500 Platform. mSystems 4, e00029-e00019. doi: 10.1128/mSystems.00029-19

Kenya Ministry of Health. (2021). Siaya County HIV and AIDS Strategic Plan: 2015/16 - 2018/2019. Available at: https://nacc.or.ke/?mdocs-file= 3787\&mdocs-url=false\#: :text=Siaya $\% 20$ County $\% 20$ is $\% 20$ clustered $\% 20$ as $\%$ 20a\%20high\%20incidence $\% 20$ and $\% 20$ high\%20burden $\% 20$ county.\&text=The \%20HIV\%20prevalence\%20among\%20the,Kenya\%20HIV\%20Estimates\%2C \%202015 (Accessed February 9, 2021).

Kenya Ministry of Health National AIDS and STI Control Programme (NASCOP). (2020). Preliminary KENPHIA 2018 Report: Kenya PopulationBased HIV Impact Assessment (Nairobi: NASCOP). Available at: https://www. health.go.ke/wp-content/uploads/2020/02/KENPHIA-2018-PREL-REP-2020HR3-final.pdf (Accessed February 9, 2021).

Kenya National Bureau of Statistics and Kenya Ministry of Health. (2014). Kenya Demographic and Health Survey. Available at: https://dhsprogram.com/pubs/ pdf/FR308/FR308.pdf (Accessed February 5, 2021).

Kovachev, S. (2018). Defence Factors of Vaginal Lactobacilli. Crit. Rev. Microbiol. 44, 31-39. doi: 10.1080/1040841X.2017.1306688

Lewis, F. M. T., Bernstein, K. T., and Aral, S. O. (2017). Vaginal Microbiome and Its Relationship to Behavior, Sexual Health, and Sexually Transmitted Diseases. Obstet Gynecol 129, 643-654. doi: 10.1097/AOG.0000000000001932

Lewis, A. L., and Laurent, L. C. (2020). USPTF 2020 Recommendations on Screening for Asymptomatic Bacterial Vaginosis in Pregnancy. JAMA 323, 1253-1255. doi: 10.1001/jama.2019.22311

Liu, C. M., Hungate, B. A., Tobian, A. A. R., Ravel, J., Prodger, J. L., Serwadda, D., et al. (2015). Penile Microbiota and Female Partner Bacterial Vaginosis in Rakai, Uganda. mBio 6 (3), e00589. doi: 10.1128/mBio.00589-15

Low, N., Chersich, M. F., Schmidlin, K., Egger, M., Francis, S. C., van de Wijgert, J. H., et al. (2011). Intravaginal Practices, Bacterial Vaginosis, and HIV Infection in Women: Individual Participant Data Meta-Analysis. PloS Med. 8, e1000416. doi: 10.1371/journal.pmed.1000416

Masha, S. C., Owuor, C., Ngoi, J. M., Cools, P., Sanders, E. J., Vaneechoutte, M., et al. (2019). Comparative Analysis of the Vaginal Microbiome of Pregnant Women With Either Trichomonas Vaginalis or Chlamydia Trachomatis. PloS One 14, e0225545. doi: 10.1371/journal.pone.0225545

McKinnon, L. R., Achilles, S. L., Bradshaw, C. S., Burgener, A., Crucitti, T., Fredricks, D. N., et al. (2019). The Evolving Facets of Bacterial Vaginosis: Implications for HIV Transmission. AIDS Res. Hum. Retroviruses 35, 219-228. doi: 10.1089/aid.2018.0304

Mehta, S. D., Nandi, D., Agingu, W., Green, S. J., Bhaumik, D. K., Bailey, R. C., et al. (2020). Vaginal and Penile Microbiome Associations With HSV-2 in Women and Their Male Sex Partners. J. Infect. Dis. jiaa529. doi: 10.1093/infdis/jiaa529

Meinshausen, N., and Bühlmann, P. (2010). Stability Selection. J. R Stat. Soc. B Stat. Method. 72, 417-473. doi: 10.1111/j.1467-9868.2010.00740.x

Naqib, A., Poggi, S., Wang, W., Hyde, M., Kunstman, K., and Green, S. J. (2018). "Making and Sequencing Heavily Multiplexed, High-Throughput 16S Ribosomal RNA Gene Amplicon Libraries Using a Flexible, Two-Stage PCR Protocol," in Gene Expression Analysis (New York, NY: Humana Press), 149-169.

National AIDS and STI Control Programme. (2015). The Kenya HIV Testing Services Guidelines (Nairobi: National AIDS and STI Control Programme (NASCOP) Ministry of Health). 
National AIDS, STI Control Programme and Ministry of Health, Kenya. (2015). Algorithms for Managing Common STI Syndromes (Nairobi: NASCOP). Available at: http://www.nascop.or.ke/index.php/recently-launchedguidelines/.

Nelson, T. M., Borgogna, J. C., Michalek, R. D., Roberts, D. W., Rath, J. M., Glover, E. D., et al. (2018). Cigarette Smoking Is Associated With an Altered Vaginal Tract Metabolomic Profile. Sci. Rep. 8, 852. doi: 10.1038/s41598-01714943-3

Newman, L., Rowley, J., Vander Hoorn, S., Wijesooriya, N. S., Unemo, M., Low, N., et al. (2015). Global Estimates of the Prevalence and Incidence of Four Curable Sexually Transmitted Infections in 2012 Based on Systematic Review and Global Reporting. PloS One 10 (12), e0143304. doi: 10.1371/journal.pone.0143304

North, B., and Oldham, M. (2011). Preclinical, Clinical, and Over-the-Counter Postmarketing Experience With a New Vaginal Cup: Menstrual Collection. J. Womens Health 20 (2), 303-311. doi: 10.1089/jwh.2009.1929

Noyes, N., Cho, K.-C., Ravel, J., Forney, L. J., and Abdo, Z. (2018). Associations Between Sexual Habits, Menstrual Hygiene Practices, Demographics and the Vaginal Microbiome as Revealed by Bayesian Network Analysis. PloS One 13, e0191625. doi: 10.1371/journal.pone.0191625

Nugent, R. P., Krohn, M. A., and Hillier, S. L. (1991). Reliability of Diagnosing Bacterial Vaginosis Is Improved by a Standardized Method of Gram Stain Interpretation. J. Clin. Microbiol. 29, 297-301. doi: 10.1128/jcm.29.2.297-301.1991

Otieno, F. O., Ndivo, R., Oswago, S., Pals, S., Chen, R., Thomas, T., et al. (2015). Correlates of Prevalent Sexually Transmitted Infections Among Participants Screened for an HIV Incidence Cohort Study in Kisumu, Kenya. Int. J. STD AIDS 26 (4), 225-237. doi: 10.1177/0956462414532447

Palarea-Albaladejo, J., and Martin-Fernandez, J. A. (2015). Zcompositions - R Package for Multivariate Imputation of Left-Censored Data Under a Compositional Approach. Chemometr Intell. Lab. Syst. 143, 85-96. doi: 10.1016/j.chemolab.2015.02.019

Paliy, O., and Shankar, V. (2016). Application of Multivariate Statistical Techniques in Microbial Ecology. Mol. Ecol. 25 (5), 1032-1057. doi: 10.1111/ mec. 13536

Phillips-Howard, P., Nyothach, E., ter Kuile, F., Omoto, J., Wang, D., Zeh, C., et al. (2016). Menstrual Cups and Sanitary Pads to Reduce School Attrition, and Sexually Transmitted Reproductive Tract Infections: A Cluster Randomised Controlled Feasibility Study in Rural Western Kenya. BMJ Open 6, e013229. doi: 10.1136/bmjopen-2016-013229

Phillips-Howard, P. A., Otieno, G., Burmen, B., Otieno, F., Odongo, F., Odour, C., et al. (2015). Menstrual Needs and Associations With Sexual and Reproductive Risks in Rural Kenyan Females: A Cross-Sectional Behavioral Survey Linked With HIV Prevalence. J. Womens Health (Larchmt) 24, 801-811. doi: 10.1089/ jwh.2014.5031

Population Reference Bureau. (2021). Status Report on Adolescents and Young People in Sub-Saharan Africa: Opportunities and Challenges. United Nations Population Fund 2012. Available at: http://www.prb.org/pdf12/status-reportyouth-subsaharan-Africa.pdf (Accessed March 22, 2021).

Ralph, S. G., Rutherford, A. J., and Wilson, J. D. (1999). Influence of Bacterial Vaginosis on Conception and Miscarriage in the First Trimester: Cohort Study. BMJ 319, 220-223. doi: 10.1136/bmj.319.7204.220

Ravel, J., Gajer, P., Abdo, Z., Schneider, G. M., Koenig, S. S. K., McCulle, S. L., et al. (2011). Vaginal Microbiome of Reproductive-Age Women. PNAS 108, 46804687. doi: 10.1073/pnas.1002611107

Schwebke, J. R., Muzny, C. A., and Josey, W. E. (2014). The Role of Gardnerella Vaginalis in the Pathogenesis of Bacterial Vaginosis: A Conceptual Model. J. Infect. Dis. 210, 338-343. doi: 10.1093/infdis/jiu089

Sherrard, J., Wilson, J., Donders, G., Mendling, W., and Jensesn, J. S. (2018). 2018 European (IUSTI/WHO) International Union Against Sexually Transmitted Infections (IUSTI) World Health Organisation (WHO) Guideline on the
Management of Vaginal Discharge. Int. J. STD AIDS 29, 1258-1272. doi: $10.1177 / 0956462418785451$

Sommer, M., Caruso, B. A., Sahin, M., Calderon, T., Cavill, S., Mahon, T., et al. (2016). A Time for Global Action: Addressing Girls' Menstrual Hygiene Management Needs in Schools. PloS Med. 13 (2), e1001962. doi: 10.1371/ journal.pmed.1001962

Torondel, B., Sinha, S., Mohanty, J. R., Swain, T., Sahoo, P., Panda, B., et al. (2018). Association Between Unhygienic Menstrual Management Practices and Prevalence of Lower Reproductive Tract Infections: A Hospital-Based Cross-Sectional Study in Odisha, India. BMC Infect. Dis. 18, 473. doi: 10.1186/s12879-018-3384-2

Torrone, E. A., Morrison, C. S., Chen, P. L., Kwok, C., Francis, S. C., Hayes, R. J., et al. (2018). Prevalence of Sexually Transmitted Infections and Bacterial Vaginosis Among Women in Sub-Saharan Africa: An Individual Participant Data Meta-Analysis of 18 HIV Prevention Studies. PloS Med. 15, e1002511. doi: 10.1371/journal.pmed.1002511

van de Wijgert, J. H., Borgdorff, H., Verhelst, R., Crucitti, T., Francis, S., Verstraelen, H., et al. (2014). The Vaginal Microbiota: What Have We Learned After a Decade of Molecular Characterization? PloS One 9 (8), e105998. doi: 10.1371/journal.pone.0105998

van Eijk, A. M., Zulaika, G., Lenchner, M., Mason, L., Sivakami, M., Nyothach, E., et al. (2019). Menstrual Cup Use, Leakage, Acceptability, Safety, and Availability: A Systematic Review and Meta-Analysis. Lancet Public Health 4 (8), e376-e393. doi: 10.1016/S2468-2667(19)30111-2

Verstraelen, H., Verhelst, R., Vaneechoutte, M., and Temmerman, M. (2010). The Epidemiology of Bacterial Vaginosis in Relation to Sexual Behavior. BMC Infect. Dis. 10, 81. doi: 10.1186/1471-2334-10-81

Zevin, A. S., Xie, I. Y., Birse, K., Arnold, K., Romas, L., Westmacott, G., et al. (2016). Microbiome Composition and Function Drives Wound-Healing Impairment in the Female Genital Tract. PloS Pathog. 12 (9), e1005889. doi: 10.1371/journal.ppat.1005889

Zhang, J., Kobert, K., Flouri, T., and Stamatakis, A. (2014). PEAR: A Fast and Accurate Illumina Paired-End reAd mergeR. Bioinformatics 30, 614-620. doi: 10.1093/bioinformatics/btt593

Zou, H., and Hastie, T. (2005). Regularization and Variable Selection via the Elastic Net. J. R Statist Soc. B 67, 301-320. doi: 10.1111/j.14679868.2005.00503.x

Zulaika, G., Kwaro, D., Nyothach, E., Wang, D., Zielinski-Gutierrez, E., Mason, L., et al. (2019). Menstrual Cups and Cash Transfer to Reduce Sexual and Reproductive Harm and School Dropout in Adolescent Schoolgirls: Study Protocol of a Cluster-Randomised Controlled Trial in Western Kenya. BMC Public Health 19, 1317. doi: 10.1186/s12889-019-7594-3

Conflict of Interest: The authors declare that the research was conducted in the absence of any commercial or financial relationships that could be construed as a potential conflict of interest.

Publisher's Note: All claims expressed in this article are solely those of the authors and do not necessarily represent those of their affiliated organizations, or those of the publisher, the editors and the reviewers. Any product that may be evaluated in this article, or claim that may be made by its manufacturer, is not guaranteed or endorsed by the publisher.

Copyright (c) 2021 Mehta, Zulaika, Otieno, Nyothach, Agingu, Bhaumik, Green, van Eijk, Kwaro and Phillips-Howard. This is an open-access article distributed under the terms of the Creative Commons Attribution License (CC BY). The use, distribution or reproduction in other forums is permitted, provided the original author(s) and the copyright owner(s) are credited and that the original publication in this journal is cited, in accordance with accepted academic practice. No use, distribution or reproduction is permitted which does not comply with these terms. 